\title{
$\mathcal{T}_{\text {International }}^{\text {Insport Forum }}$
}

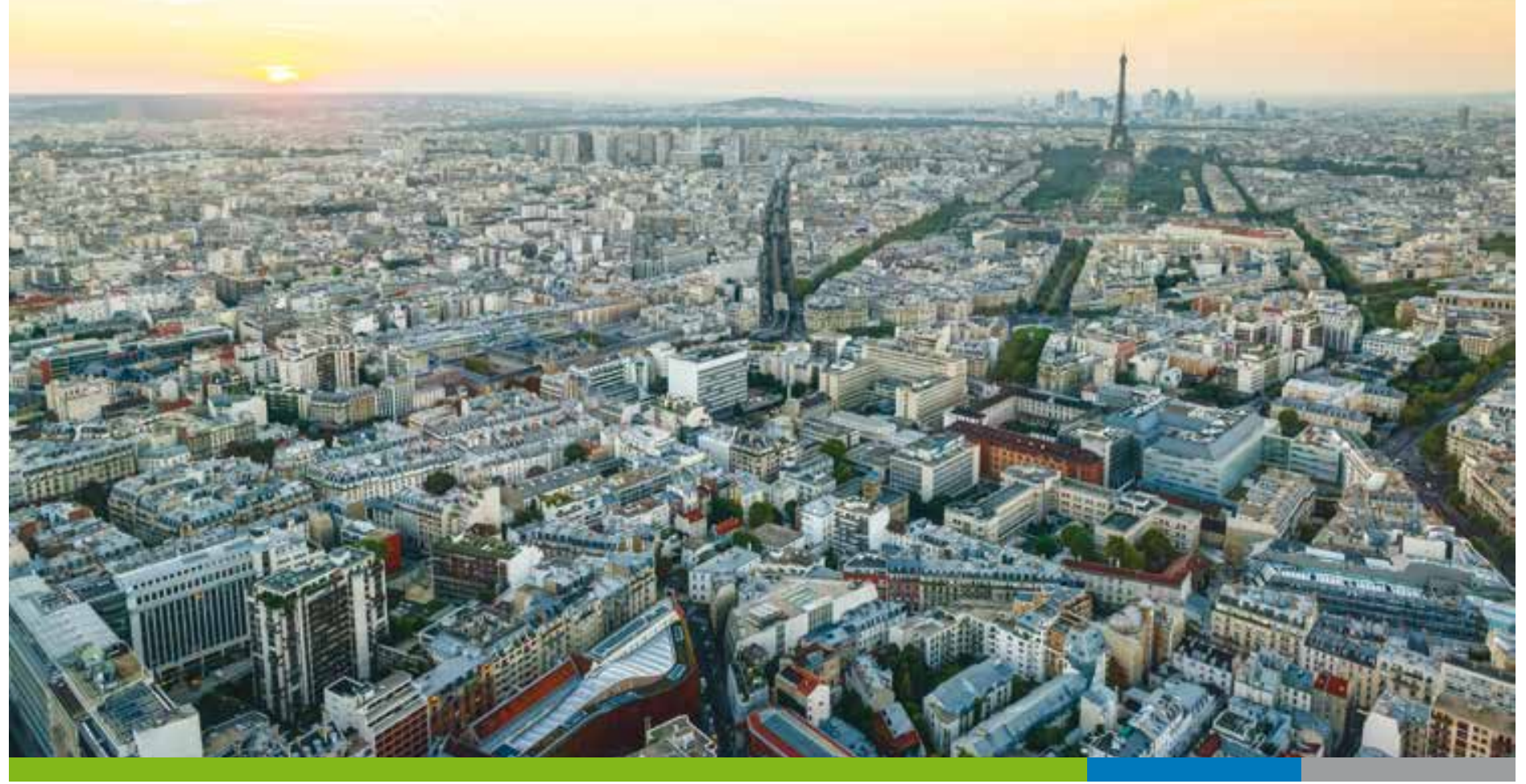

Appraising

Transformational Projects

The Case of the Grand Paris Express

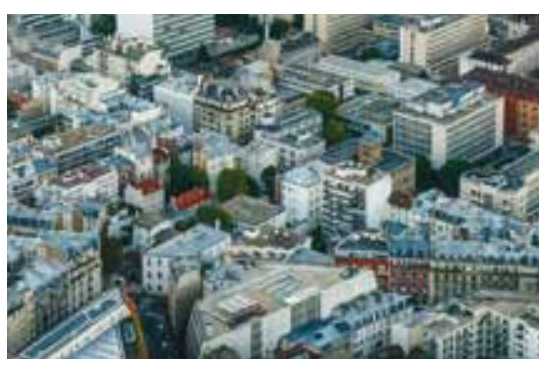

Country-Specific Policy Analysis 


\section{Appraising Transformational Projects}

The Case of the Grand Paris Express

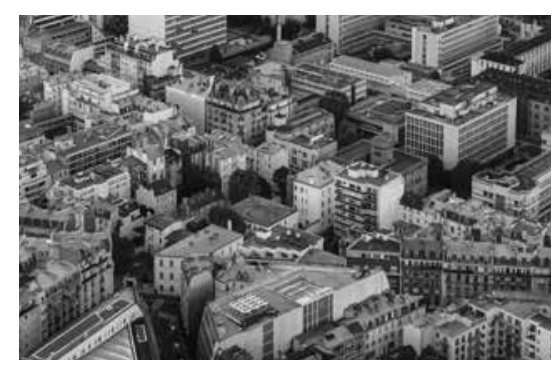

Country-Specific Policy Analysis 


\section{INTERNATIONAL TRANSPORT FORUM}

The International Transport Forum at the OECD is an intergovernmental organisation with 54 member countries. It acts as a strategic think tank with the objective of helping shape the transport policy agenda on a global level and ensuring that it contributes to economic growth, environmental protection, social inclusion and the preservation of human life and well-being. The International Transport Forum organises an Annual Summit of ministers along with leading representatives from industry, civil society and academia.

The International Transport Forum was created under a Declaration issued by the Council of Ministers of the ECMT (European Conference of Ministers of Transport) at its Ministerial Session in May 2006 under the legal authority of the Protocol of the ECMT, signed in Brussels on 17 October 1953, and legal instruments of the OECD.

The Members of the Forum are: Albania, Armenia, Australia, Austria, Azerbaijan, Belarus, Belgium, Bosnia and Herzegovina, Bulgaria, Canada, Chile, People's Republic of China, Croatia, Czech Republic, Denmark, Estonia, Finland, France, Former Yugoslav Republic of Macedonia, Georgia, Germany, Greece, Hungary, Iceland, India, Ireland, Italy, Japan, Korea, Latvia, Liechtenstein, Lithuania, Luxembourg, Malta, Mexico, Republic of Moldova, Montenegro, Netherlands, New Zealand, Norway, Poland, Portugal, Romania, Russian Federation, Serbia, Slovak Republic, Slovenia, Spain, Sweden, Switzerland, Turkey, Ukraine, United Kingdom and United States.

The International Transport Forum's Research Centre gathers statistics and conducts co-operative research programmes addressing all modes of transport. Its findings are widely disseminated and support policy making in Member countries as well as contributing to the annual summit.

Further information about the International Transport Forum is available at www.internationaltransportforum.org

\section{DISCLAIMER}

Any findings, interpretations and conclusions expressed herein are those of the authors and do not necessarily reflect the views of the International Transport Forum or the OECD. Neither the OECD, ITF nor the authors guarantee the accuracy of any data or other information contained in this publication and accept no responsibility whatsoever for any consequence of their use.

This document and any map included herein are without prejudice to the status of or sovereignty over any territory, to the delimitation of international frontiers and boundaries and to the name of any territory, city or area. 



\title{
Acknowledgements
}

\author{
Société \\ du Grand \\ Paris
}

This report was commissioned jointly by the International Transport Forum and the Société du Grand Paris and co-funded by the two organisations. The analysis for the report was undertaken by Peter Mackie and Tom Worsley of the Institute for Transport Studies at the University of Leeds and James Laird, Peak Economics Ltd. The authors are grateful to Stephen Perkins of the International Transport Forum and Kurt Van Dender of Organisation for Economic Cooperation and Development and JeanClaude Prager and Emile Quinet of the Société du Grand Paris for their comments and contributions. 



\section{Table of contents}

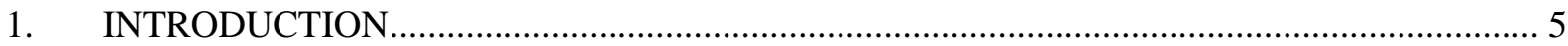

2. TRANSPORT PROJECTS AND ECONOMIC APPRAISAL ……....................................... 7

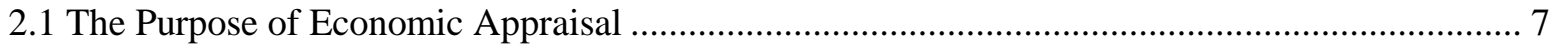

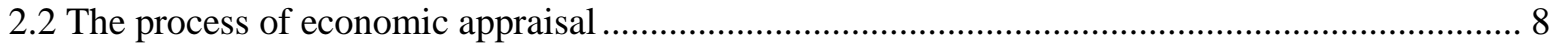

2.3 Setting the Reference Case - conventional schemes ............................................................... 8

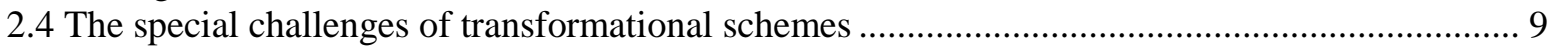

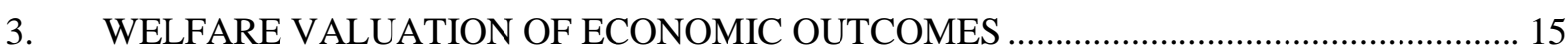

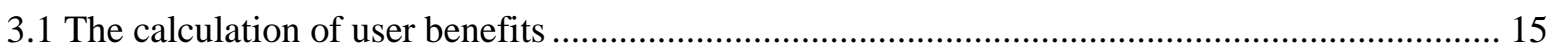

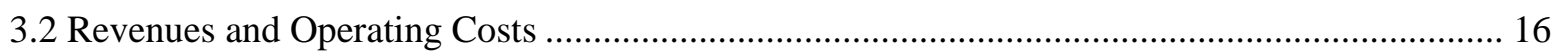

3.3 Wider economic impacts - a typology of market failures ........................................................ 16

3.4 Potential for interactions, double counting and relevance to infrastructure type ........................ 23

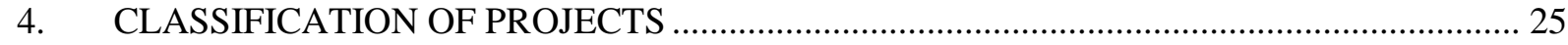

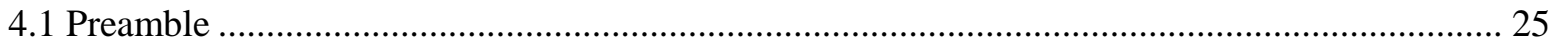

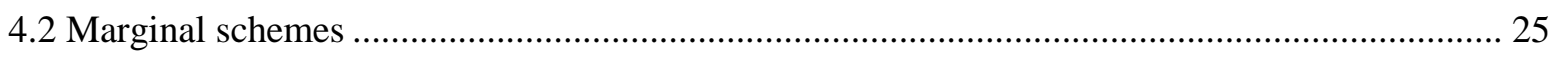

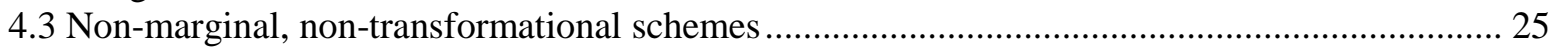

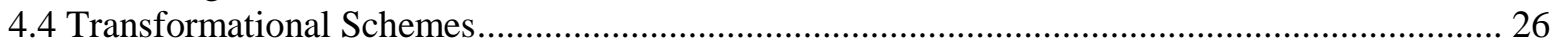

5. THE APPRAISAL OF TRANSFORMATIONAL PROJECTS: The analytical challenges ...... 29

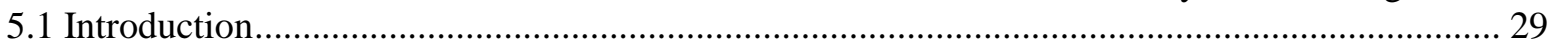

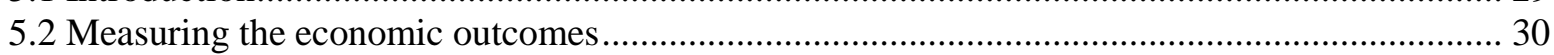

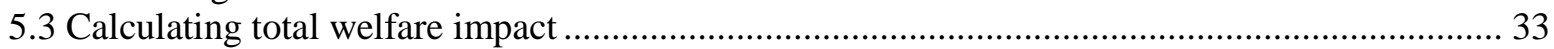

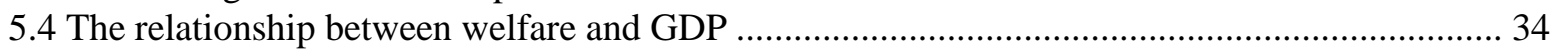

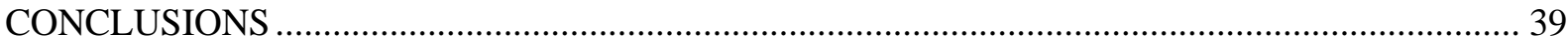

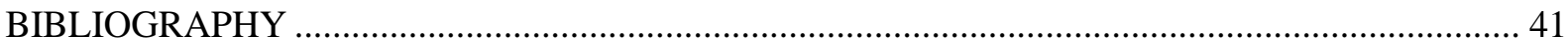

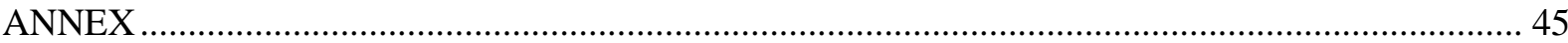

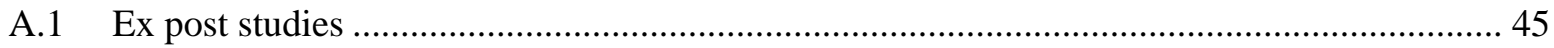

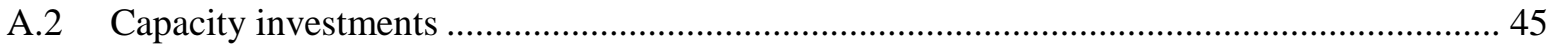

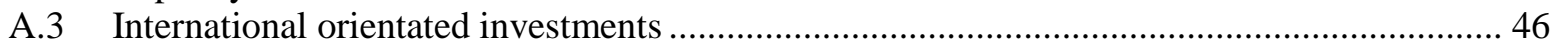




\section{Figures}

4.1 Project and appraisal classification

\section{Tables}

Table 1. Comparison of GDP 48 


\section{Introduction}

A well-executed economic appraisal can demonstrate to the decision maker whether investment in a project represents a good use of resources and inform the decision to approve the scheme, postpone it or reject it. But the micro-economic partial equilibrium foundations of cost-benefit analysis are challenged by projects such as the Grand Paris Express that are designed to transform the level of economic development in the area it will serve. Conventional cost-benefit analysis examines incremental change and assumes that the project itself has only a marginal effect on overall economic performance. Representation of the economic system in which population, employment and income are contingent upon whether or not the scheme is undertaken is a major challenge. The definition of the counterfactual do-nothing or do-something-else case is also difficult with such projects as, given their hoped-for impact on regional growth, some major alternative interventions are clearly likely to be undertaken if the project itself does not go ahead. Crucially, the practical implications of concepts such as the economic benefits of agglomeration have to be unravelled to predict the behaviour of the sectors whose responses to changes in accessibility are key determinants of the outcome of investment in the project. The aim of this report is to review the conduct of appraisal in these challenging conditions.

In December 2011, the International Transport Forum hosted the Roundtable Major Transport Infrastructure Projects and Regional Economic Development. ${ }^{1}$ This roundtable debated the special issues that arise in the appraisal of transformational transport projects. Two projects were the subject of papers to that meeting: the Grand Paris Express orbital rail proposal in Paris and the Crossrail 1 radial line through Central London which is currently under construction. The subject of the roundtable proved to be fertile ground for debate and in April 2014 the authors were commissioned to provide a follow-up report on certain questions.

In this paper we start from the premise that the scope of the appraisal of transport projects should depend upon the presence (or absence) of various forms of market failure. We review briefly the purposes and processes of transport appraisal in Chapter 2 before setting out a typology of market failures in Chapter 3. In Chapter 4 we then turn to ask what distinguishes marginal, non-marginal and transformational projects in appraisal terms and what special challenges are created by transformational projects. In chapter 5 we consider the methods available for the appraisal of such projects and the challenges faced. Our key messages are presented in Conclusions.

We are clear that the state of the art is far from settled but that an account of the effects of such projects on the accessibility and attractiveness of city economies and the places within them is essential to an informed decision process. So a key challenge for the future is to marry together the engineeringeconomic approach to the appraisal of transport projects with the insights of the New Economic Geography to produce a comprehensible account of how and whether transport infrastructure transforms city regions' economies.

$1 \quad$ Major Transport Infrastructure Projects and Economic Development, International Transport Forum Roundtable 154, OECD publishing (forthcoming). The papers prepared for the roundtable and the summary and conclusions of the debate are available on the web at http://www.internationaltransportforum.org/jtrc/roundtables.html 



\section{Transport projects and economic appraisal}

\subsection{The Purpose of Economic Appraisal}

Economic appraisal is aimed at enabling decision makers to reach well informed choices. Appraisal is relevant to a wide set of choices. These range from decisions about whether to proceed with a scheme which comprises both transport and land use and other changes, aimed at transforming the level and structure of economic activity across a large area, such as the Grand Paris Express project, to decisions about options for managing bus flows in a city centre or the by-pass of a small town. Depending on the complexity of the scheme and the range of its expected impacts, the process can be a simple and largely although not exclusively a mechanistic one, or it can require extensive analysis specific to the scheme and make more demands on the judgement of the decision-maker.

A well-executed economic appraisal can demonstrate to the decision maker whether investment in a project represents a good use of resources and hence inform the decision about whether to approve the scheme, postpone it or reject it. In most cases the decision is also concerned with the choice between mutually exclusive alternatives, for example alternative alignments, capacity and sequencing of elements of the scheme. Judgement on its own is unlikely to provide a satisfactory alternative to the use of a formal process of economic appraisal. It is difficult for a decision maker, in particular for an elected representative, to reach an unbiased view about the merits of an individual project. In absence of a formalised appraisal process, there is simply too much information for an individual to retain to enable that person to reach a consistent set of priorities. Many countries have a long tradition of relying on economic appraisal to inform the components of the decision process such as public deliberation, statutory planning inquiry and final Ministerial decision.

There are many reasons for preferring economic appraisal to any other decision making process. Transport infrastructure is long lived and most of the costs are sunk since the assets rarely have an alternative use. Schemes are built in large increments, are largely irreversible, and structure the development of the transport network and influence land use for a very long period.

While some infrastructure, such as investment in port and airport capacity is often commercial, roads, many railways and most local transport projects lack a revenue stream which is adequate to repay the costs, either because charging at the point of use is not a practical or cost effective option or because the project is designed to provide services below cost to meet a policy objective such as improving social or regional equity. Furthermore, all transport infrastructure schemes have impacts on society which extend beyond the interests of any users who might contribute directly to the costs. So ex ante appraisal of schemes from the perspective of the impact on the economy and society is required, and documents such as the UK Treasury Green Book set out the general rules which should be followed.

Economic appraisal, when based on the use of cost benefit analysis, provides decision makers with information about the case for a project when viewed from a national perspective. Analysis is an essential input to the process of empowering a decision-maker and enabling that decision-maker to reach a judgement which can be explained and defended as part of the requirements of the democratic process. This includes the contribution of appraisal information to the discourse of deliberative decision making. 
But the micro-economic partial equilibrium foundations of the conventional transport cost benefit analysis are challenged by projects such as the Grand Paris Express or the Jubilee Line Extension to the London Underground, serving London's Docklands, schemes which are intended to transform the level of economic development in the areas which they serve. The aim of this paper is to review the conduct of appraisal in these challenging conditions.

\subsection{The process of economic appraisal}

The process of economic appraisal is by now well established. As has been shown in a recent study (Mackie, Worsley and Eliasson (2014 forthcoming), there is a remarkable commonality between the methods adopted in the different countries that rely on project appraisal to inform decision makers. The approach starts by identifying the objectives of the transport scheme or of the wider project or policy, in terms of improving accessibility and hence the quality of journeys experienced by transport users, whether for people or for goods and whether for business or travelling for other purposes. Other likely objectives and impacts of the intervention are also identified, since decision makers need to know about the full implications of any project that they might approve and are often under a national or Europeanwide statutory duty to take account of all of the significant impacts of the project.

The appraisal process is invariably based on estimating the first round impacts of a transport scheme or policy. It focuses on the improvements in accessibility, measured in terms of the traveller's experience, in particular through the time savings and associated benefits including reductions in unreliability and in overcrowding on public transport. The implications for safety and for the local and global environment also form part of the information provided to decision makers. Importantly, the approach taken in the appraisal assumes people and firms respond to the opportunities offered by the new infrastructure to change where they locate and the pattern of their activities. Predicting changes in the spatial distribution and level of economic and social activity for every transport project is a complex task with many uncertainties. But in the case of many transport schemes, the imperfections in the markets affected by the scheme are thought not to be significant enough to merit the additional complexity and uncertainty of using an alternative to the first round set of benefits delivered by the scheme to appraise it, though it is clear that this first round, while providing a measure of the total surplus, does not give a true indication of the pattern of final impacts of the investment.

Since appraisal is concerned with the impacts of a specific project, it is a comparative process, intended to show the difference that the proposal is expected to make when compared with an alternative scenario. Given that one of the reasons for conducting an appraisal is to help decision makers decide whether it is in the national interest to approve and in most cases to fund a proposal, this counterfactual or reference case needs to be one of 'do-nothing' or at the most one of a minimum level of investment consistent with the continuing operation of the network. The specification of the reference case can have a substantial impact on the case for the proposal, in particular in those cases in which demand is forecast to increase on congested networks. As well as the reference case, several or many do-something alternatives are likely to warrant appraisal so that choices between these can be informed by the appraisal. The specification of alternatives and of the reference case is a well-established part of the process through which governments deliver transport policies and schemes.

\subsection{Setting the Reference Case - conventional schemes}

There are several levels at which the reference case and options might be set. For the majority of schemes, such as reducing congestion at a motorway intersection, improving safety at an accident black spot or improving reliability at a busy railway junction, the choice of options is constrained by the government's policy objectives. The reference case might be one of 'do-nothing' or of undertaking some 
low cost improvements to ameliorate the existing situation. Invariably the set of options is restricted to improvements to the infrastructure and perhaps some local traffic management options, such as imposing a speed limit to improve local air quality. More radical options, such as managing demand through pricing, for example by implementing road user congestion charging or increasing rail fares, are not usually, but should be, within the set of options to be considered in the case of any individual scheme.

Decision makers generally rely on engineering judgement, informed by public consultation and the views of other stakeholders, in order to identify the alternative solutions to addressing the transport problem identified. The first stage of the appraisal process is to sift out the options which are unlikely to deliver value for money either on the grounds of high costs or failure to meet the objectives. The transport model and the economic appraisal are then used to provide an assessment of the costs and benefits of each of the remaining short listed options and of consequences of failing to take any action. For a typical scheme, the specification of the reference case and the options is relatively uncontroversial. In the case of the UK, there is a transport policy framework, set out in the Department for Transport's Draft National Policy Statement for the National Roads and Rail Networks (2013); the options and the reference case are restricted to those which address the defined transport problems of capacity, reliability, accessibility and carbon. In the case of France, the "Scénario de reference" should include, not only the related planned infrastructures, but also the evolution of prices and regulations pertaining to transport.

Certain technical problems arise in the forecasting and modelling of traffic in scenarios in which traffic on the mode being modelled is predicted to grow over the longer term. High levels of congestion or crowding in the do-minimum reference case some years after the scheme being appraised would have opened prevents, in many cases, the transport model from reaching a stable equilibrium as traffic in the model switches between one congested or overcrowded route and another. The UK Department for Transport has adopted the convention of capping demand 15 years after the date of the projected opening of the scheme. While this might appear as a purely technical concern, it illustrates the challenges faced by analysts, engineers and policy makers in establishing a realistic do-minimum reference case not just at the opening date but many years ahead.

\subsection{The special challenges of transformational schemes}

Establishing a reference case for a scheme which is aimed at achieving wider outcomes than the resolution of a case and context dependent transport problem provides a challenge which extends beyond the competence of the transport engineer, analysts and local stakeholders. The challenge extends both to the setting of the reference case and the conduct of the appraisal

The opportunity to build a transformational project occurs rarely. For example, in Great Britain, a country with a long tradition of marginal projects and a scepticism of "grands projets", a view which was endorsed in the Eddington Transport Report (Eddington, 2006), it is arguable that the only large transformational projects built during the last 25 years have been the Channel Tunnel with its rail link to London andthe Jubilee Line Extension to London's Docklands. The proposed new airport located in the Thames estuary and the HS2 rail link between London, the West Midlands and the north might be other such schemes. Because such schemes are 'once in a lifetime' opportunities, the evidence about the expected outcomes of such schemes and the role of transport in realising those outcomes is much thinner than is the evidence that supports the case for the more typical marginal transport scheme.

Moreover, mega projects themselves differ in their objectives: the improvements in accessibility within the Ile de France might have very different outcomes from the reductions in travel time delivered by the TGV Est to Strasbourg. So the analyst responsible for appraising a mega project has to understand the 
evidence on transport's role in delivering these wider objectives and stretch the methodology beyond the conventional cost benefit and associated transport modelling methods.

The objectives of a transformational project invariably extend beyond the direct transport outcomes. Many such projects are the expression of a national or regional vision aimed at changing the composition and level of economic activity through a programme of investment which combines transport, land use development, public realm and civic amenities. Such schemes inevitably generate debate, discussion and many disparate views, often reinforced by strong political support or opposition. The assessment of the project shifts from a focus on the case for transport infrastructure to one which encompasses the entire investment package. While much of the cost of land use change and development will be incurred by the private sector, such schemes often require a public sector contribution in cash or in kind, such as investment in schools and other public services to pump prime the project. Yet the conventional transport appraisal methods do not extend to provision for estimating the benefits of such changes.

The more ambitious transformational projects are aimed at influencing the macro-economy. Such projects are concerned with influencing domestic and foreign investors. The aim is to project at a national or at a world-wide level the image of a good place to do business. It goes well beyond any quantitative estimation of the impact on the country's economic performance of the direct improvements in accessibility delivered by the project. The influence of image is not to be underestimated: one plausible reason for London's prosperity during the recession might be the turn-round in the performance of the transport network from one of the worst to one of the best in Europe since the turn of the century. Similarly, the Grand Paris scheme is a part of an overall strategy to make the Ile de France area more dynamic

A necessary element of a conventional cost benefit appraisal is the specification of the reference case in order to provide a means of estimating the change in consumer surplus generated by the options under consideration. Specification of the reference case in the case of a transformational project is rarely straightforward. Because of the scope of the scheme and the breadth of the objectives, it often requires a political judgement about which options and policies are to be included in the set of proposals to be compared and which should be excluded from the set of options to be appraised. For example, in the case of the proposed HS2 rail link from London to the north, in the reference case prepared by the project promoters, levels of overcrowding on the existing network would become extreme in absence of increases in rail fares, a policy option ruled out by government ministers. An alternative scenario which provided for the upgrading of the existing rail routes between London and Birmingham was drawn up. This option was rejected by the Minister on the grounds that it failed to deliver the objective of delivering enough capacity to meet forecast demand.

In the case of the Grand Paris Express, the level of development planned exceeds anything that could be accommodated in the Paris region in absence of the proposal. The reference case becomes one which includes differences not only in accessibility but also in the composition and level of employment and in the population and in its spatial distribution: one of the conditions which has to accompany the scheme is, according to many experts, a clearly defined housing policy.

Transformational projects present the analyst with two challenges. The first is that of conducting the appraisal, given that the established methods are restricted to the direct transport related outcomes, while the second is the challenge of setting up the reference case. This latter challenge occurs because the wider set of outcomes anticipated from the scheme moves decisions about alternatives away from the railway of highway engineer, working with stakeholders and other consultees, into a more political sphere. The policy context of the decision has been widened from the transport outcome to the wider one of restructuring the regional economy. One of the aims of the proposed high speed line between London 
and the north of England is to address the economic imbalance between north and south. The analyst faces the problem that, while appraisal is widely used for transport schemes for the reasons given in the first part of this section of the paper, it is not generally a formal part of process of decision making on general economic policy.

It might be argued that the UK government ought to have undertaken an appraisal of a programme of investment in research and training, centred on new institutions in the North of England, as an alternative to a high speed railway as a means of rebalancing the economies of the two regions. But investment in research and in training programmes, while carefully monitored and evaluated to help decision makers understand 'what works', is not subject to the same level of ex ante scrutiny as a transport scheme. So there are no reliable and approved forecasting and appraisal methods for such policies which would enable the analyst to compare the costs and benefits of such an option with a transport scheme aimed at achieving both transitional outcomes as well as delivering benefits to transport users. The contrast between the mandatory use of cost benefit appraisal in the case of transport schemes and its more sporadic use in other the sectors which are either dependent on public funding or subject to economic regulation is not a uniquely British problem. The recently published report for the Commissariat Général à la Stratégie et à la Prospective (2013) notes a similar focus on transport in France and recommends the extension of cost benefit appraisal to other public sector decisions.

The failure to establish a comprehensive set of options to be compared with the promoter's preferred scheme in the case of transformational projects is exacerbated by tendency of a government department or other institution to act as the champion of the scheme. If the project is developed by a transport authority, whether a government department or an institution responsible for delivery of transport services, then the alternatives to the preferred scheme will be restricted to those over which the authority has some competence. A national transport department, led by the minister, might be expected to champion a transport solution to what is initially identified as a transport problem or encompassing an important transport dimension. A regional authority, while possibly taking a more holistic view, will have no concern about impacts which occur outside its sphere of authority, including the impact of a scheme on employment displaced from outside the authority's region. Strong direction from the centre, for example from the ministry of finance or of strategic planning, is required if options to be considered are to be extended beyond those which are delivered by the department responsible for transport.

This extension of the impacts identified in the project appraisal from the changes in accessibility to the wider changes in labour and product markets provides a further challenge to the conventional transport cost benefit analysis. And while, as noted above, there is considerable commonality between the methods used in the many countries that have adopted evidence based transport assessment methods, there has been less progress in developing practical methods for incorporating all of these wider impacts in a project appraisal. The various approaches, described in section 3 this paper, either aim at complementing, through the inclusion of wider benefits that belong within the welfare economic framework, or provide a different and alternative metric of the impacts of the proposal based on estimates of changes in GVA or in employment levels.

Appraisal serves a number of purposes, largely concerned with the allocation of the transport budget, as outlined earlier in this section of the paper. Transformational projects generally provide an exception to this, since they are in most cases too costly to be funded directly from the budget allocated by the Ministry of Finance or Treasury to the minister responsible for transport. The aim of the appraisal is no longer one which helps prioritise schemes to be funded from the transport budget (or to be included as options within a national transport plan). But appraisal continues to have a purpose by providing the government with some indication of the case for proceeding (or not) with the proposal on the grounds that all public spending needs to deliver benefits in excess of its costs, although the difficulty of 
specifying the reference case and the uncertainty about estimating some of the wider impacts risks reducing the robustness of the economic appraisal. In addition, the transport model, which underpins the economic appraisal, provides transport engineers with the projections of demand by link, flows at interchanges and other inputs needed to optimise the design and capacity of the project.

In the case of the Grand Paris Express project one cannot escape very difficult questions such as:

- In the business as usual scenario, what do we expect to happen to the economy of the Paris region, the location of activities, jobs and population?

- What will the consequences be for travel volumes, congestion, crowding and reliability?

- As well as the Reference Case, are there other Do Something options, for example improved radial capacity, which would have to be considered?

In the case of what is effectively an entire regional plan supported by a transport sector infrastructure investment, it becomes necessary to investigate the future of key high value sectors of the Paris (or Ile de France) economy such as the financial services sector, the research and development sector and so on. It is as important to ask what will happen without the Grand Paris Express as what will happen with it, so that the credibility of the response properties of the economic and social system can be exposed to scrutiny. The modelling tools are discussed in section 3, but it is almost inevitable that some form of scenario planning approach will be required to provide the alternative futures for the key sectors which drive other sectors and ultimately transport and land use patterns.

Less formal approaches might also be of value to decision makers. One possible method would take an objectives led approach and provide decision makers with the narrative, explaining the linkages through which the transport scheme, together with the other policy interventions, might deliver the desired outcomes, taking care that the narrative should exclude any strategic influence from the stakeholders. Evidence for such linkages would be used to strengthen the explanation of how the project would deliver the transformational change expected of it. Although such an approach fails to provide the decision maker with information about whether the scheme exceeds the 'go/no go' threshold (which arguably is provided by the economic appraisal, despite the potential flaws when applied to transformational projects, as described above), it would have value in ensuring that decision makers understood the interventions which are additional to the transport investment and which are needed to deliver the desired outcomes.

An approach which provides the narrative about the expected transmission of the transport related outputs into wider economic outcomes is not without its risks. The evidence behind these impacts is less certain than for the first round effects and is more dependent on the circumstances of the scheme. There is a risk in such an approach that the experts commissioned to write the narrative will emphasise the more favourable of the range of outcomes. Recourse to a second opinion, as proposed in the report for the Commissariat Général à la Stratégie et à la Prospective (2013), should help to manage this risk. 
The finding that the reliance that can be placed on the case for a scheme, as estimated through the transport appraisal, is inversely related to the size of the scheme or to the extent and range of the objectives it is expected to deliver is an uncomfortable one for the transport analyst. But conventional cost benefit analysis can still play an important role in the implementation of transformational projects. Appraisal provides a planning tool to help decision makers prioritise the separable components parts of a transformational project. For example, appraisal can help decision makers understand which segment of the Grand Paris Express project would provide the greatest benefits and hence how to organise the letting of contracts and allocate the funds over the construction period. Although any such appraisal still requires the construction of a reference case, the realism of this option is less of an issue if the decision to proceed with the project has already been taken. Such an approach may facilitate project planning in a series of steps which can reflect the economic case for different sections of route, for the key interchanges with the rest of the network and how best to integrate transport provision with the planned development and relocation of economic activity - the myriad of choices below the top level yes/no question 



\section{Welfare valuation of economic outcomes}

\subsection{The calculation of user benefits}

As a preliminary it must be stated that there are exceptional challenges in modelling and forecasting the transport and wider economy impacts of such a scheme as the Grand Paris Express. This intervention changes the capacity of the region, changes the radial/orbital balance, and creates potential which may or may not be utilised. There is, therefore, a high degree of uncertainty about the impact of the scheme both on the transport market and the wider regional economy and on the trajectory of development over time. Even more than is usually the case, the appraisal involves an assessment of the difference between uncertain quantities, where the margin of uncertainty could dwarf the differences. What follows should all be read in that context.

A complete analysis of a scheme such as the Grand Paris Express will include various dimensions such as the social and distributional impacts, the deliverability of the project and the funding and financing models to be used. In this paper we focus on the economic efficiency benefits of the scheme as one component of the overall business case.

The evidence to date indicates that user benefits form the majority of the welfare benefits of a transport scheme (including when wider economic impacts are included). Their robust calculation is therefore critical to the estimation of all transport projects, including the transport investments associated with the Grand Paris Express.The methods used to calculate user benefits when land uses are fixed and projects are marginal are well established. For large transport projects, such as the Grand Paris Express, the transport investments will be expected to switch destinations, modes and routes and to induce travel demand. The Rule of Half (Neuberger, 1971) should therefore be used. If however transport cost changes are likely to be large or new modes are to be introduced to the locality, very likely in the case of the Grand Paris Express where some zone pairs will receive new direct fast connection, then the change in consumer surplus has to be estimated either through a direct integration of the demand function or through the process of numeric integration (Nellthorp and Hyman, 2001).

A complication to the calculation of user benefits arises if land uses are expected to change. Transport is a derived demand, and the benefit of the transport cost reduction is in fact felt in the net utility derived from the activity being undertaken at the destination. If the utility at the destination remains fixed then the change in utility can be measured by looking at transport costs alone. If however the utility of the activity at the destination alters then this identity no longer holds (Neuberger, 1971; Martinez and Araya, 2000; Bates, 2006) at least for non-marginal transport changes. A simple example of such scenario, as given by Bates, is one in which city centre public transport improvements increase the number of people in a city centre, which encourages new businesses to open making the city centre a more attractive place. The utility to travellers of being at the destination (the city centre) has therefore altered as a second order effect of the transport investment.

Very little work, either methodologically or empirically, has been undertaken to examine the implications of the bias inherent in ignoring the change in utility at the destination when land uses change as a consequence of a transport improvement. Geurs et al. $(2006,2010)$ estimate the level of error 
associated with using the standard rule of half when land uses change. They find large biases, but it is difficult to assess the extent to which they come from externalities or from the consequences of large, non-marginal changes for which the $\mathrm{RoH}$ is an approximate measure. Our appreciation is that large scale land use changes within the region are contingent upon, indeed a key rationale for, the Grand Paris Express, so that an integrated land use and transport model is required. In these conditions, the issue of evaluating the benefits to travellers in terms of simultaneous changes in accessibility and zonal attractiveness is therefore likely to be a significant one, and should be an active subject of research.

\subsection{Revenues and Operating Costs}

There are no special issues under this heading but as usual, the appraisal requires a set of assumptions to be made about fares policy and service levels so that incremental revenue and cost calculations can enter the appraisal. These should be consistent with the measures of impedance used in the demand modelling work. Assumed changes in fares over time should be explicitly represented. These are common issues in public transport appraisal but resolving them could be demanding for such a large and important scheme. Consistency in the modelling and appraisal in the treatment of fares is important.

\subsection{Wider economic impacts - a typology of market failures}

Wider economic impacts only have relevance in a transport CBA if markets are distorted - that is price does not equal marginal social costs elsewhere in the economy. They are also only relevant if economic outcomes change as a result of the intervention: that is if output changes, productivity changes and employment changes relative to the reference case.

We now present five such distortions and consider whether these distortions are material to the robustness of a transport CBA. These distortions relate to: agglomeration economies, labour taxes, imperfect goods markets, involuntary unemployment, thin labour markets/search costs and distortions in the land market. We discuss the market distortions in this order to reflect the evidence base and experience in exploring these effects. The distortions with the largest evidence base are discussed (i.e. agglomeration economies and labour taxes) first and those which really have only been identified at a conceptual level (thin labour markets and land market distortions) last.

\section{Agglomeration externalities}

Areas of high economic mass are more productive than other locations. A city the size of Paris is more effective than two cities half the size, other things being equal, because of this agglomeration effect. Good inter-city links facilitate regional specialisation in particular industries generating localisation economies $^{2}$. An increase in effective economic mass can be created by increasing accessibility and this in turn increases productivity in many of the sectors that choose such locations.

Agglomeration economies have been the main focus of attention in the literature on the wider economic impact of transport interventions (van Exel et al., 2002; Laird, Nellthorp and Mackie, 2005; DfT, 2005a; Eddington, 2006; Venables, 2007, Graham, 2007). They arise as a consequence of the technological externalities that occur when economic agents in transport using sectors of the economy are brought closer together by a transport improvement. By bringing these agents closer together labour productivity is raised above and beyond what would be expected from the transport efficiency saving alone. The numerous micro-economic linkages between economic agents, brought closer together, generate the

2 Localisation economies are agglomeration economies associated with the economic mass of an industry, whilst urbanisation economies are agglomeration economies associated with the size of an urban area. 
externalities which, collectively and at a localised level, give rise to aggregate increasing returns or agglomeration economies. Venables (2007) in his highly influential paper shows that the productivity and output impact caused by the agglomeration externality is additional to transport user benefits.

There exists a substantial literature on the variation in worker productivity with agglomeration size (see for example Rosenthal and Strange, 2004; Melo et al., 2013). There exists a substantial variation in the size of these agglomeration effects. To a large extent this is down to whether studies control for the heterogeneity of labour. Workers with high skills and high levels of ability cluster to the larger agglomerations. This worker heterogeneity has been shown to be responsible for most of the spatial variation in productivity (Combes et al., 2008; Mion et al., 2009; D'Costa et al., 2012; D'Costa and Overman, 2013; Gibbons, Overman and Pelkonen, in press). It is essential therefore that the agglomeration elasticities used when calculating the welfare impacts of agglomeration have been estimated using a method that controls for worker heterogeneity. Our observations are that this is not always done, and as a consequence can result in unrealistic estimates of productivity changes.

With a project such as the Grand Paris Express we would expect significant agglomeration effects. Assessment of agglomeration effects for the project does suggest they will be significant, but highly linked to migrations of populations from the rest of France and foreign countries towards the Paris area; unfortunately knowledge about the effects of the scheme on these migrations is rather limited (Quinet 2014). The project will have a scale effect on largest agglomeration in France and will also result in a significant re-distribution of economic activities. One intention is that clusters in knowledge based industries coupled with a better inter-linking between universities and industry will be developed and/or enhanced. These will have productivity gains associated with knowledge spillovers. So agglomeration economies are relevant, although representing restructuring effects in modelling and appraisal is very challenging.. Conversely the re-distribution of economic activity from other parts of France and from central Paris may have negative agglomeration impacts. These too are estimated as it is the net gain that is of interest from a welfare perspective (as well as from the perspective of national decision-makers).

The agglomeration effects of transport schemes can be quite significant. Elhorst and Oosterhaven (2008) using a Spatial Computable General Equilibrium model for the Netherlands appraise four variants of a maglev high speed train line with variants that strengthen the core Randstad area of the Netherlands and variants that link the core to the periphery. They find increases in labour productivity are between $12 \%$ and $21 \%$ of transport user benefits depending on the maglev (magnetic levitation) train variant appraised - with the higher value associated with the variants that strengthen the economic core of the Netherands (i.e. the Randstad). Using a partial equilibrium approach DfT (2005 p8) found that Crossrail, a large rail capacity enhancement in Central London, agglomeration generates an additional 24\% of economic benefits relative to user benefits. As Crossrail re-distributes employment to the most productive part of the UK the value of its indirect effects are the largest one would expect to find in the UK. Typically agglomeration effects will have a much lower added value than Crossrail. For example the Eddington Study found the sum of agglomeration and imperfect competition effects average $22 \%$ of user benefits for urban schemes, $7.4 \%$ for surface access projects to international gateways and $9.1 \%$ for inter-urban corridors (Eddington, 2006 Figure 1.5 p.129). In the case of the Grand Paris Express, the ratio of these agglomeration effects to the traditional benefits has been estimated to be $27 \%$ (central scenario), but is highly dependent on the assumptions about the migrations towards the Ile de France area induced by the scheme (Quinet 2014). 
Over the past decade, a number of countries have developed methods of estimating agglomeration benefits as an addition to transport user benefits, the best known of which is the UK' ${ }^{3}$. Other countries which have some form of guidance on agglomeration impacts include New Zealand, Sweden and the US, and France is engaging in that way - so, there is an evidence base which can be used to inform assessment of the agglomeration impact.

\section{Labour tax}

Venables (2007) identified the relevance of labour taxes to transport cost benefit analysis. Labour taxes create a distortion in the labour market that mean workers do not receive a wage equal to their marginal product of labour, and employment levels lie below those that would occur in an undistorted labour market. This is the case even in the absence of structural unemployment which is considered in the next section. Here we consider the divergence between the social and private benefit of an additional unit of output/employment in a fully employed economy. Venables (2007) showed that if a transport scheme displaces economic activity to a more productive location, where wages are higher ceteris paribus, then transport user benefits do not capture the full welfare gain of the intervention. Similar arguments can be made for tax wedge additionality to transport user benefits when a transport scheme can be shown to expand employment (in terms of hours worked) at a national level - through for example lowering the cost of commuting thereby making entering the labour market more attractive and feasible to those on the margin of entering the labour market. In a case study of the London rail proposal Crossrail, DfT (2005a) found that these additional surpluses due to labour tax distortions were $15 \%$ larger than the agglomeration benefits - so they can be quite substantial. Recent work at the University of Leeds suggests that in the case of bus subsidy options, these tax wedge benefits were $9-10 \%$ of the direct transport user and operator benefits (Johnson et al,2014).

For the Grand Paris Express project this market distortion will be very relevant because it is expected, relative to the reference case, that employment at national level will be expanded as a result of the scheme and also that jobs will be shifted between locations with different levels of productivity.

In the UK in terms of application, the DfT guidance requires the use of a land use transport interaction model to estimate how job locations shift between areas with differing levels of productivity. The guidance provides analysis regarding how productivity levels vary between areas. The guidance also adopts a simple approach to the modelling of an expansion of labour supply - assuming a perfectly competitive economy and the only constraint on worker participation in the labour market is commuting costs. Reductions in commuting costs then increase labour supply. In both situations the additional income tax revenue (the UK labour tax) is the additional welfare surplus. The assumption that the operation of the labour market is essentially supply-constrained, and the use of the single elasticity and tax wedge proportion are somewhat simplistic and would benefit from deeper investigation by sector and class of labour. A careful review of the tax wedge effect of increased employment and output under the French tax regime might be required if it does not already exist, but the principle of including allowance for this distortion in transport sector CBA does not seem controversial.

\section{Imperfect competition}

Venables and Gasiorek (1999) first identified the relevance of imperfect competition in the goods and services markets as being a source of distortion in the economy relevant for transport CBAs. Imperfect competition occurs as firms may hold market power if they engage in product differentiation or become

3 DfT's WebTAG unit A2-1 (Wider Impacts) sets out the parameters and data required for estimating these benefits at scheme level 
large relative to their market. The latter is particularly true in geographically isolated areas, where as a consequence of geography firms act as local monopolists or oligopolists. If imperfect competition exists then a transport induced expansion of output will give rise to an additional welfare impact stemming from this market - as under imperfect competition output is not at its socially optimum level.

Central to the argument of the empirical relevance of imperfect competition is evidence on price marginal cost mark-ups. There is ample evidence at an international level that perfect competition does not prevail. For example for $10 \mathrm{EU}$ countries Badinger (2007) estimates mark-up factors of price above marginal costs of approximately 1.3 for manufacturing and construction and 1.37 for services for the late 1990s. Christopoulou and Vermeulen (2008) also find evidence that rejects the perfect competition hypothesis with average price-cost factors of 1.37 in 8 Euro area countries and 1.31 in the US. They also find that the price-cost margins are not uniform with significant variation by industry and country lying behind the observed averages.

In terms of empirical relevance to a transport CBA Venables and Gasiorek (1999) using synthetic data find that imperfect competition could be very relevant to transport cost benefit analysis. They estimate that in a two region one sector economy with imperfect competition the additional welfare impact from an expansion in output is between 30 and $40 \%$ of the change in consumer surplus derived by business and freight users. This result relates to a partial equilibrium analysis, in that changes induced in other sectors of the economy (the general equilibrium effects) are of no net social value. Davies (1999) and Newbery (1998) who undertook reviews of the Venables and Gasiorek research challenge this finding and consider the 30-40\% figure to be an upper limit. For the UK, SACTRA (1999) took the view that indirect effects due to imperfect competition would on average increase benefits by about $12 \%$. There appear to be very few studies of imperfect competition impacts in isolation from other impacts in the literature - other studies typically report imperfect competition impacts in combination with other types of impact (e.g. Bröcker et al., 2004; Eddington, 2006). For example Bröcker et al. (2004) using a SCGE model CGEurope found that completion of all of the TEN-T priority infrastructure projects may generate between 20 and 30\% more economic benefit than would be measured in a normal transport cost-benefit analysis arising from productivity effects and imperfect competition effects. Imperfect competition effects would be expected to drive this productivity change as the model only considered urbanisation economies which are not affected significantly by TEN-T inter-urban projects.

Drawing upon evidence collected by SACTRA (1999), the UK DfT WebTAG recommends the use of a mark-up of $10 \%$ on top of business and freight user benefits. In theory this would appear to be applicable to all transport projects which are predicted to have output effects. In practice, the DfT only applies this part of the guidance to those schemes where there are other wider impacts such as agglomeration effects present. Application of the DfT guidance gives a fairly uniform imperfect competition effect across schemes - albeit it varies with the proportion of business and freight user benefits. In reality as imperfect competition is very heterogeneous across industrial sectors (and countries) one would expect the degree of imperfect competition should vary depending on the types of businesses affected by a scheme. Markets with exceptional non-uniform tax rates such as air travel require special attention. Similar calculations for France lead to the same percentage and similar recommendations (CGSP 2013).

4 This calculation rests on the assumption that the monopolist does not price differentiate. If a monopolist is able to discriminate between consumers they will expand output towards the socially optimum level and convert some of the surplus under the demand curve to producer surplus. In this scenario there will be a lower, and at the limit zero, additional welfare impact in the product market. With a price differentiating monopolist average price-cost margins will not be a good indicator of market power. To date this issue has not been explored in the literature, and this paper does not return to it, but it is noted that such an argument undermines the general case for including changes in output in imperfectly competitive markets in a transport cost benefit analysis. 


\section{Unemployment and underemployment effects}

It has long been recognised in cost benefit analysis literature that expanding employment in areas with involuntary unemployment has a welfare value (Boardman, 2011 pp105-108; Haveman and Farrow, 2011). Modern cost benefit analysis guides (e.g. EC, 2008 p53) explicitly recognise this through the use of shadow wages. It is therefore surprising that in a survey of transport appraisal practice in the EU Odgaard, Kelly and Laird (2005) found that, aside from Germany, no national transport appraisal cost benefit analysis guidelines explicitly account for such welfare benefits despite pockets of high and persistent unemployment remaining at a local, and sometimes regional levels. If involuntary unemployment exists and is reduced by the project, then transport user benefits will not capture the full social value of expanding employment - that is there is additionality. Involuntary unemployment can be caused by an immobile workforce, skill mis-matches or some forms of labour market regulation.

Underemployment occurs when workers cannot get work that they are skilled to undertake (e.g. a graduate engineer working as a shop assistant) or they cannot work as many hours as they wish to (e.g. working part-time when a full-time job is desired). In a perfectly competitive environment this should not happen. This is a variation of the involuntary unemployment argument, in that the market wage in different labour market segments lies above the reservation wage at observed levels of employment. Some form of labour market distortion or friction prevents the market wage falling. Expanding employment in these sectors and allowing workers to increase their hours or substitute jobs for one that better suits their skills creates a welfare benefit that is not captured through transport user benefits alone.

The employment generating effects of the Grand Paris Express would be expected to have a significant impact on the local labour market. Surpluses additional to transport user benefits will occur if these local labour market changes provide jobs for unemployed or underemployed workers. This will only occur if the skillset of the unemployed and underemployed match the skill requirements of the jobs being created. Typically the long term unemployed are characterised by low skills. Such workers are not particularly mobile - it is difficult for them to move house particularly if living in social housing, and the cost of the commute is a significant barrier to employment. Part of the economic analyses for the Grand Paris Express would be to demonstrate the ability of the unemployed and underemployed at filling the jobs created by the transport investment.

Elhorst and Oosterhaven (2008) using a Spatial Computable General Equilibrium model for the Netherlands challenge the view that involuntary unemployment is not relevant to a CBA in developed economies with mature transport networks. They appraise four variants of a maglev high speed train line and find that involuntary unemployment effects in remote regions can have a substantial impact on scheme benefits. Depending on the route of the maglev line under consideration, they found that indirect effects due to involuntary unemployment may change benefits as measured in a conventional transport cost benefit analysis by between $-1 \%$ and $+38 \%$, and can also dominate agglomeration benefits. Effectively re-distributing employment in the remote region (from the economic core of the country) generates substantial efficiency benefits, whilst variants that re-enforce the economic core and redistribute employment away from the periphery generate substantial disbenefits. These disbenefits cancel out the benefits due to increased agglomeration and productivity in the economic core. Their results are, however, case dependent. In this instance they arise as a consequence of a labour market failure relevant to the Netherlands - that of national minimum wages by industry. This is extremely important. In the Netherlands there is a legal mechanism which means an excess supply of labour will prevail in certain regions when the market clearing wage is below the minimum industry wage. This suggests that a crucial question for the Grand Paris Express appraisal is how the regional and national labour market is expected to operate across sectors and skill levels, taking account of relevant institutional considerations such as minimum of wages/ maximum hours of work. 
The above approach involves a tacit assumption that the economy will be operating under conditions of structural unemployment or underemployment for many years, possibly for the entire appraisal period, and that the scheme will have a clear effect on this unemployment/underemployment. Such an assumption needs to be based on sound economic reasoning - see our earlier discussion in Chapter 2 on the definition of the reference case. Furthermore for this distortion to be relevant there needs to be a clear economic argument that links the transport investment to a reduction in structural unemployment or underemployment Such an argument is provided in the Elhorst and Oosterhaven study, but it is highly context specific. It is likely therefore that this market distortion will only be relevant to a subset of projects - we discuss this further in section 3.4 below. An alternative approach might be to view impacts on local structural unemployment due to social deprivation or locational disadvantage as primarily redistributive in nature. This could be considered within a social and distributional analysis which however is outside the scope of this paper.

\section{Search costs and thin labour market effects}

Pilegaard and Fosgerau (2008) were the first authors to identify the relevance of search costs as a market distortion in the appraisal of transport infrastructure. They integrated a job search model into a SCGE model populated with Danish economic data. The model was then used to evaluate a transport quality improvement that increases labour supply at a national level. They report significant additional benefits of around $30 \%$ of commuter user benefits arising from the labour market (for an economy with no labour tax) as a consequence of search imperfections. Laird and Mackie (2014) similarly find significant additional benefits from reducing search costs for the immobile categories of the workforce who are in the main likely to be lower skilled.

In job search models (see Rogerson, Shimer and Wright, 2005 for a survey) unemployed workers have difficulties in finding information on job vacancies, and even if there are many jobs within the workers' neighbourhood only a small percentage of them become vacant at any one time. From the perspective of the employee, labour markets are therefore thin - even if there are many firms. This then gives firms market power over workers (Bhaskar, Manning and To, 2003; Manning, 2003). With this market power firms will only employ labour up until the point that marginal cost of labour equals its marginal revenue product - which is below the level of employment that would occur under perfect competition. An expansion of employment therefore creates a surplus additional to user benefits.

The presence of thin labour markets is a little studied area, but what evidence that does exist (e.g. Card and Krueger, 1994) tends to focus on low skilled industries that pay the national minimum wage. For thin labour markets to be relevant to the appraisal of a transport investment a clear economic argument that demonstrates how the transport investment will expand employment in these low skilled industries will be necessary. Like with structural unemployment and underemployment effects it is clear that these effects are highly context specific and we discuss projects where they may be relevant in section 3.4. We also note that the evidence base on the scale of the distortion is very sparse and in much need of development. Any transport appraisal that was based on the valuation of such effects would therefore need to undertake primary research in the first instance into the size of the distortion created by the presence of such effects. This is a major research theme, due to the poor estimates of the parameters involved in these mechanisms and to their likely importance within the appraisal.

\section{Land use externalities}

Intrinsic to the estimation of wider economic impacts is land use change. Expansions in output and employment will require some substitution between the inputs to production: labour, private capital and 
land. Land use change is therefore fundamental in the assessment of wider economic impacts. For the Grand Paris Express the centrality of land use change to the overall strategic plan is unquestionable.

There is the potential for significant distortions in the land market. Development of land is in itself a source of significant externalities. Land use development will increase the burden on existing infrastructure - transport, water, sewage, energy as well as social infrastructure such as schools imposing costs on existing users of the infrastructure ${ }^{5}$. There also exists an environmental impact if greenfield sites are developed - in terms of lost habitat and negative biodiversity impacts. In the presence of such externalities prices need correcting to ensure development is at an appropriate scale. Planning regulations act as a substitute for such a correction - ideally allowing development where the external costs are low and ensuring, where external costs are high, mitigation is included as part of the development (e.g. expanding infrastructure capacity). Of course planning regulations are a function of the political process and they may not properly correct for the externalities. In England it has been argued that such regulations are too tight (Cheshire and Sheppard, 2005) leading to extreme price discontinuities of land. Cheshire (2013) cites that intensively farmed land near London is worth $£ 10,000$ per hectare, whilst if it could be used for housing it would be worth $£ 8,000,000$. Such discontinuities may be present in Paris too. Should they be present in Paris and the Grand Paris Express allows a change in land use at some sites in Paris this may then be a source of additionality - as the marginal benefits of changing the use of the land will exceed the marginal social cost of that development.

Venables, Laird and Overman (2014) also argue that two other failures may occur in the land use market: a co-ordination failure and a failure stemming from 'lumpy' or 'non-marginal' investments in land. They argue that the multiple actors required for land use development to succeed requires co-ordination. This constitutes a market failure. Transport infrastructure (and other infrastructure) may solve this coordination problem. They also argue that some developments can have a minimum scale associated with them. As a consequence the private sector may not develop land, even if the marginal benefits exceed the marginal costs. A transport investment by raising the marginal benefits can facilitate the development. But this point is highly specific and should be estimated carefully, especially to avoid strategic biases.

All three of these arguments represent sources of additionality in the transport investment appraisal. As with the arguments associated with the labour market (increasing labour supply in the presence of a labour tax, reducing unemployment and underemployment and increasing labour supply in the presence of search costs) a careful economic analysis demonstrating the presence and size of the market failure would be required. As far as we are aware there have been no empirical studies on the level of additionality to transport user benefits from market distortions in the land market. ${ }^{6}$ Care would be needed to define the additional marginal value correctly; it is certainly not simply the difference between the land value in one use and another. As with thin labour markets it is likely that primary research on the presence and size of land market distortions would be needed before any attempt at incorporating them into an appraisal could be made - this is in direct contrast to say agglomeration impacts where a sizeable evidence base already exists.

$5 \quad$ Not all land development externalities will be negative. In remote areas development can sustain communities by ensuring the shops, schools, etc. remain financially viable.

6 We note that negative environmental externalities are typically not valued in cost benefit analyses (aside from carbon, noise and air pollution) and that these externalities are typically taken into account through some form of framework or multiple criteria analysis. Whilst in transport appraisal it is good practice to include the congestion externalities imposed on users of the transport network from changes in land use (see earlier discussion on user benefits), we are unaware of examples where congestion costs on other infrastructure (energy, water, telecommunications, schools, healthcare, etc.) are included. These should also be included if the marginal costs of land development do not fully reflect the marginal social cost. 


\subsection{Potential for interactions, double counting and relevance to infrastructure type}

The nature of transport and land-use systems is that there is interaction which is equilibrated by mechanisms such as congestion and crowding. Achieving a reasonable level of consistency in the modelling and appraisal is both demanding and necessary. Then, within the appraisal, if user and operator benefits are the bedrock of the appraisal, we need to take care only to count additional wider impacts and to disallow any impacts which are the same transport benefits transmitted through into the wider economy. Provided care is taken the market distortions identified above can be included and do not overlap with user benefits and should be included in the welfare efficiency analysis. There is the possibility that the additional surpluses maybe supra- or sub-additive, particularly when occurring within the same market (e.g. the labour market). In Chapter 5 (section 5.3) we discuss the methods that can be used for calculating total welfare impact under conditions of multiple market failures, though it is worth noting at this point that no definitive statement can be made on the question of sub- or supra-additivity to our knowledge as no research on the topic has been undertaken.

Despite the fact that the relevance of different market distortions is dictated primarily by market conditions rather than by type of infrastructure or policy we can say something about the types of market distortions relevant to certain infrastructure types. This is because market conditions are expected to vary spatially and the types of transport investments also vary spatially.

Agglomeration economies are most relevant to transport projects that affect urban areas, particularly the centres of these urban environments - so are typically important for urban rail schemes and other forms of mass urban transit. Labour taxes are most relevant when employment is shifted between low productive and high productive locations ceteris paribus which again points towards mass urban transit projects. Labour taxes are also relevant when employment (in terms of hours worked) expands at a national level, which points towards projects that are important at unlocking growth - which can include a whole range of projects. Imperfect labour markets are most relevant to projects which affect businesses which operate in the most distorted markets. World markets in primary sector commodities are probably the most competitive. Christopoulou and Vermeulen (2007 Table 1) find for the Euro area mark-up ratios above marginal cost of 1.18 for manufacturing and construction and 1.56 for market services. This reflects both the levels of regulation (including market entry) as well as other barriers to entry particularly associated with knowledge and global competition. As market service based companies are located in urban areas we would once again expect mass transit type schemes to be most relevant.

Structural unemployment, underemployment and thin labour markets are typically urban phenomena affecting the low skilled. Transport interventions are not typically the most useful policies for addressing these market distortions - skills training, education and housing interventions are more relevant. Where transport investment creates growth in low skilled jobs (e.g. by facilitating the construction or expansion of a factory assembly line or food processing plant) these distortions would become relevant. As such jobs are typically manufacturing jobs freight transport investments (road and rail based) would be most relevant to these types of market failure.

Land market distortions have not been studied empirically, but one would conjecture such distortions to be most relevant in urban environments - possibly on the periphery of urban areas at the interface between agricultural land and the urban settlement. Rail based and road based peri-urban projects would therefore all be relevant to these sort of market failures. 



\section{Classification of projects}

\subsection{Preamble}

In reality schemes may be envisaged as a continuum. If they are to be classified at all, this should not be primarily by size but by the nature of their impacts. For example, a modest project which opens previously unusable land for use in an urban economy where land is scarce may have significant effects on that economy. A large inter-urban project may have significant but very diffuse benefits because of the wide range of traffics and O/D pairs benefitting from it. Also it is necessary to consider the cost of modelling and appraisal relative to the payoff: this is the case for a degree of proportionality in appraisal. So the cases we define below are illustrative of different points on a spectrum. Caution is required because these categories are somewhat arbitrary and real schemes may not fall neatly into one category or another in every respect. The differences in appraisal treatment of these categories are illustrated in Figure 4.1.

\subsection{Marginal schemes}

When market imperfections are relatively small for scheme users and the environmental and safety external impacts are taken into account, then the conventional economic welfare analysis based on direct user and operator benefits works well and provides a coherent framework for estimating the scheme benefits. Impacts on the spatial distribution of land use are small and largely irrelevant to the decision maker. Inevitably many schemes that can be classified as marginal have some impact on local economic activity. For example, a scheme to provide a by-pass of a small town will reduce the level of passing trade as motorists no longer stop at the town's cafes or shops and transfer that trade to other now relatively more accessible locations. But the improvement to the local environment might attract other trips to the by-passed town. Because these effects are generally very local, small and involve displacement rather than net changes in economic activity, they are generally ignored in the appraisal.

\subsection{Non-marginal, non-transformational schemes}

For a significant proportion of schemes, and a larger proportion of the transport budget, simply ignoring the additional wider impacts is no longer regarded as satisfactory practice. Such schemes probably would still make use of a transport model assuming fixed land-use, although some might take account of induced land use change. We classify schemes in this category if some of the sources of market failure discussed in section 3.3 are relevant and material to the scheme appraisal. The UK Department for Transport's WebTAG includes a category of Wider Impacts (TAG Unit A2-1) which cover agglomeration externalities, the cost/price mark-up and labour supply impacts. A recent review of transport appraisal practice showed that several countries now take account in their appraisal guidance of some of the wider impacts of a transport scheme (Mackie and Worsley, 2013).

Many of the techniques used to appraise these schemes remain grounded in the economic welfare based calculus of consumer surplus using an extended partial equilibrium approach which we denote 'CBA plus'. However, some have been used to provide estimates of changes in Gross Value Added or in levels of employment, either deriving these estimates from the welfare based estimates or from the use of alternative approaches to the conventional cost benefit method. These are discussed in section 5.2 below. 
Figure 4.1 Project and appraisal classification

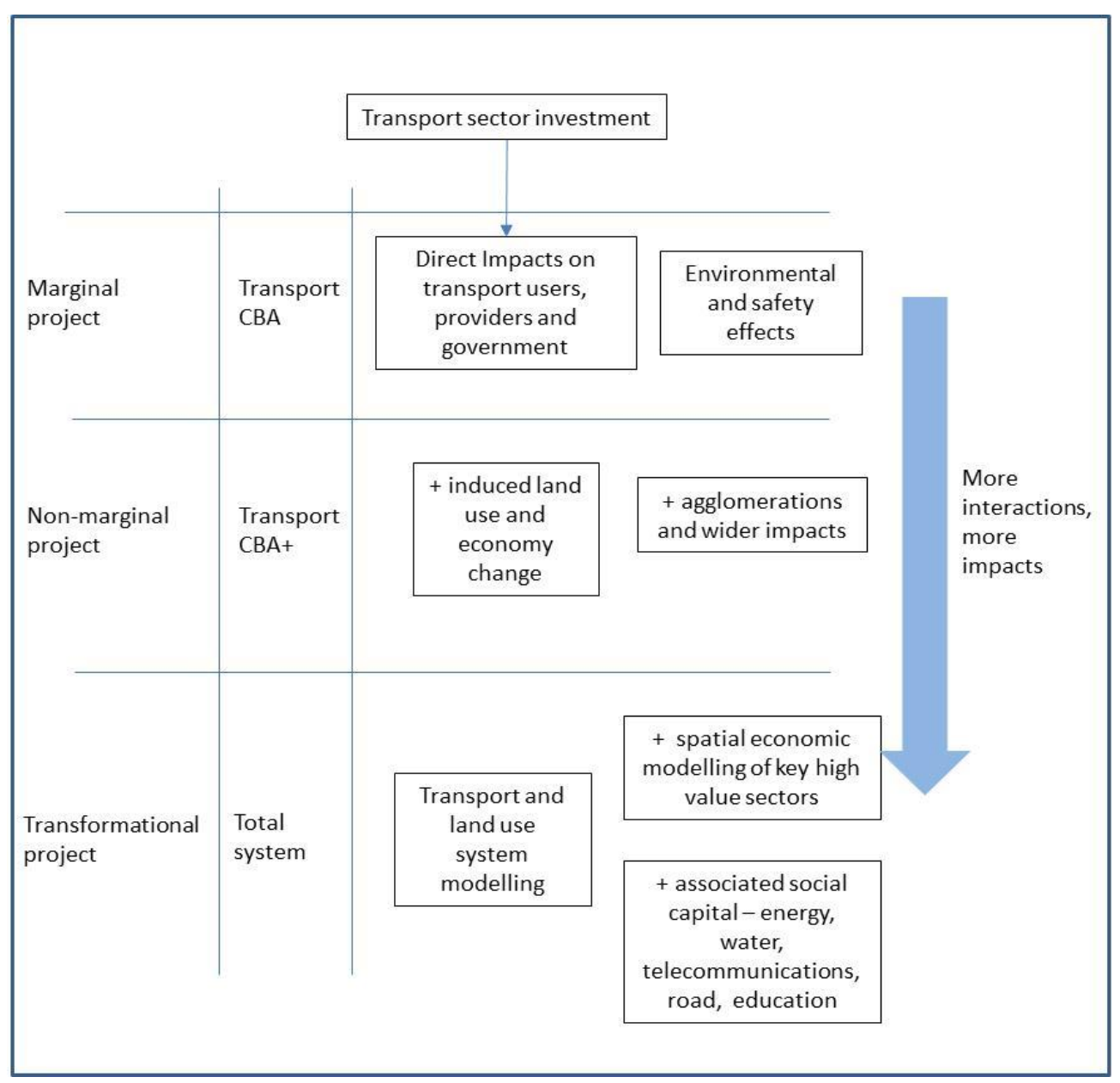

Source : Authors

\subsection{Transformational Schemes}

The boundary between a non-marginal project and a transformational project is fuzzy. It could be related partly to size or scale, and partly to the economic conditions in the region. But we think the main distinction is as follows. Transformational projects happen when changes in accessibility are associated with large changes in zonal attractiveness such that the regional economy is significantly different with the project in place than without. Very few transport projects in Britain fall into this category, but in our view the Jubilee Line Extension to Canary Wharf and Stratford is one and the possible relocation of London's hub airport from Heathrow to the Thames Estuary would be another. These are more than just transport projects and depend for their success on significant changes in land use and economic activity in the region. Frequently they are associated with overcoming rigidities in the land market and/or the need to re-plan a city.

Because the distinction between a non-marginal and a transformational project is not clear cut, a few diagnostic tests might be helpful such as: 
- Is the project's primary purpose to act as a catalyst for economic change rather than to improve the transport system?

- Will substantial investment in other sectors which are final users of transport services be needed to deliver the intended outcomes and is this an integral part of the plan?

- Is the project expected to have significant effects on the land and labour markets and on regional income and population levels? Are income effects an issue?

- Are the effects of the project likely to be felt far into the future?

At one level, these questions could be answered by assertion. But at another level the answers need to be based on evidence. The fact that a project is large does not make it transformational. Relaxing constraints on transport does not necessarily result in changes in the level and spatial distribution of economic activity. If the supply of land for these activities is very constrained, then most of the impact of the transport scheme on land use will be on the price of land rather than on the quantity supplied to facilitate the changes in economic activity. There are more restrictions on land use changes in Paris than in Central London because of the objective in Paris to maintain the sky-line in the city centre, a condition relaxed somewhat in parts of central London a decade ago. So increases in the capacity of the lines serving the city centre of Paris, even if they had an economic case in terms of the benefits to commuters of the reduction in crowding, are unlikely to have a significant impact on land use. Indeed, a key rationale of the Grand Paris Express project is to increase the supply of land which is accessible to residents and businesses in the Ile de France region and thereby to change the competitive position of the regional economy.

If it is true that the Grand Paris Express is really the centrepiece of a broader spatial economic plan in which the primary impacts are on the spatial economy as a whole, we think this opens up some very challenging questions at sector level. For example, which sectors are expected to respond to the new opportunities for development? Is their behaviour market driven or directed by planning policy? What happens in the centre of Paris if there is migration of business activity in the broadest sense to satellite cities? How will land prices adapt? What will happen to 'blue collar' Paris in between the Peripherique and the new satellites?

Of course we are scarcely well placed to answer such questions but in our view an intervention which aspires to be transformational requires an appraisal framework capable of capturing the impacts on the regional economy within its national context. It needs to operate at macro and micro levels (for key sectors) and to link to supporting sectors such as energy, water, roads and other forms of social overhead capital which are significantly impacted. Stylistically, this is a different kind of analysis frame and might be associated with more than one level of modelling and appraisal --- for example a high level model to investigate the case for the strategy and a lower level of model to consider the tactical choices within the strategy. 



\section{The appraisal of transformational projects - the analytical challenges}

\subsection{Introduction}

In this chapter we discuss approaches for evaluating welfare surplus and GDP gains for transformational projects, and compare them to approaches used to assess marginal investments. To re-iterate the discussion in the previous chapter in the case of marginal investments we expect the economy outside of the transport sector to be operating under conditions of perfect competition, thus marginal changes in the economy have no net additional welfare value to that measured by transport user benefits ${ }^{7}$. The economy is also closed. With a closed economy the change in consumer surplus is a real income gain which can be interpreted as a change in real GDP ${ }^{8}$. Relaxing this assumption and taking an intervention that gives us a step change in accessibility gives us the transformational transport project. With such a project we would expect a significant re-structuring in the economy: changes in employment, productivity and output in addition to the obvious significant changes in transport demands and costs.

Any evaluation effectively requires two steps. In the first step it is necessary to predict the economic outcomes. With a marginal transport project this is primarily changes in transport demands and costs. For a transformational transport project there is also a need to predict the changes in the economy: productivity, output and employment - this is in terms of the quantities demanded/supplied and the prices. With a transformational project land uses ${ }^{9}$ will alter. For a mixed land use and transport project such as Grand Paris Express, the land use modelling element is clearly fundamental.

The second step of an evaluation requires a valuation of the changes in the economic outcomes. Clearly the transport cost reductions hold value, but for transformational projects what value should be ascribed to changes in employment, output and productivity? Are these values already captured by transport user benefits or are they additional? In chapter 3 we have discussed why some of these changes in the wider economy have value. In this chapter we extend that discussion by considering how the different market distortions need to be combined to give an estimate of total economic welfare change.

Finally, there are issues concerning the measurement of economic outcomes. In the paper so far we have used the consumer and producer surplus framework of cost-benefit analysis, extended to cover the wider economy impacts. But decision makers are frequently interested in the impact of projects on Gross Value Added of the economy, and we compare the CBA and GVA measures in section 5.4.

7 Environmental and safety externalities are additional to transport user benefits.

8 As GDP only measures traded goods (housework is not traded for example) the traded element of the change in user benefits (business and freight user benefits) is often used as the measure of the change in real GDP.

9 Here we take land use in a broad sense - meaning any change in human activity at a location (Wilson, 1998). Thus it is not just the case that the industrial use of land is changed (agricultural to housing), but the people that use the land can also change (e.g. up-skilling). 


\subsection{Measuring the economic outcomes}

\section{The economic outcomes}

Transport quality improvements, by changing accessibility, impact on employment and output through multiple channels.

They lead to changes in productivity. Improved access to economic mass increases productivity. Reduced business travel time increases productivity as staff engaged in travel increase their time spent in more productive activities. Reduced freight travel time increases productivity as vehicle and driver utilisation increases. Through agglomeration economies increased access to economic mass leads to increases in total factor productivity. Potentially, sorting effects will lead to higher productive firms and individuals clustering to locations with higher economic mass, increasing localised productivity further though potentially at a cost to other regions. Reduced trade costs (including transport costs) between cities and regions can stimulate further regional specialisations, the gains from trade, again leading to increases in (average) productivity across the economy. Finally, ancillary investments related to the transport investment can lead to an up-skilling in the quality of the workforce or in better 'capital' assets (ICT, office premises, etc.) all of which may also increase productivity.

They lead to increased labour market participation. Real wage increases, through either higher labour productivity or reduced commuting costs, will tempt those on the margin of participating in the labour market into the labour market.

They lead to a change in the spatial location of activity. Most importantly transport impacts on the spatial location of economic activity. Economies of scale in production may be realised by firms reorganising plant locations in response to the transport quality improvement. Spatial competition is also affected. A lowering of transport costs exposes firms previously sheltered from competition to increased levels of competition. Lower productive firms then go into decline with their market share being captured by more productive firms located elsewhere - the location of economic activity has altered. Alternative destinations also become available - for example changes in transport costs alter the balance between city centre retailing and out of town retail sites. Similarly the balance between stay-at-home tourism and overseas travel is affected by the accessibility of overseas destinations. The re-distribution of economic activity means that jobs are created in some locations and destroyed in others; economic activity is displaced from one locality to another.

Transformative transport projects are important as these changes in productivity, employment and output are likely to be significant. Furthermore the spatial impacts, particularly at a local level, are very relevant. In terms of modelling the economic outcomes it is clearly important to distinguish between growth and re-distribution. Let us note also that these mechanisms interact: for instance, relocation induces agglomeration effects which in turn modify initial relocations. Of course growth to the Paris region may in fact be re-distribution from other regions in France, and growth in France may be a result of a redistribution of economic activity within Europe. Fundamentally the main drivers to growth at an aggregate level are changes in productivity and the bringing of new resources (particularly labour) into production. The economic modelling tools deployed for modelling the expected economic outcomes of the Grand Paris Express should ideally be able to measure these changes as well as the change in the spatial distribution of economic activity. This has been addressed in evaluations of the project using LUTI models Relutrans, Urbanism andPirandello. 


\section{Transport-economy modelling methods}

There exist a large range of models for predicting the impacts of regional policy, including transport investment, on the economy. Such models and methods have been described and categorised elsewhere (Vickerman, 1991; Rietveld and Bruinisma, 1998; Oosterhaven and Knaap, 2003; Wegener, 2011; MVA/ITS, 2013). This plethora of modelling methods and the rapid advances that are being made in the field gives rise to a variety of different modelling method categorisations. It is worth noting that, although a large range of models exists, experience of their practical application to transport schemes is very limited, with the exception of land use transport interaction (LUTI) models and even their applications are limited - partly this reflects the state of the art and partly this reflects the fact that a lot of projects are marginal - as we have defined marginal in Chapter 4. From the perspective of this paper, Wegener's (2011) classification is useful as it focuses specifically on the modelling of economic development in a spatial sense. Wegener identifies six modelling genres operating at two different spatial scales - the inter-regional level and the intra-regional level.

At the inter-regional level he identifies three modelling genres:

- Regional production function models. In classic production function models the inputs are capital, labour and land. To these other location specific factors have since been added such as infrastructure (as in Aschauer's (1989) seminal work), and in more recent applications accessibility and other 'soft' location factors have been added.

- Multiregional input output (MRIO) models. These use the classic Leontif (1966) multi-regional input-output framework, where inter-industry and interregional trade flows are a function of technical input-output coefficients and transport costs. Models that utilise this framework will often treat final demand as exogenous (that is transport investment cannot grow the overall size of the economy), instead transport investment affects growth at a regional level (i.e. it affects the spatial distribution of economic growth).

- Spatial computable general equilibrium (SCGE) models. These models follow the ideas of new economic geography introducing economies of scale and imperfect competition to an inputoutput framework. They also differ from multi-regional input output models as economic growth is endogenous to the model, and prices adjust to reflect supply side constraints that can crowd out economic growth (see Bröcker and Mercenier, 2011 for a review within a transport context).

At the intraregional level Wegener also identifies three genres for modelling business location:

- spatial interaction location models which take changes in trade flows from an input-output framework as an indicator of changes in industry location;

- bid-rent location models that have firms acting as profit maximisers choosing locations given land prices (where land prices are endogenous to the model); and

- utility-based location models which are similar to bid-rent models, but include multiple location factors and convert them to a utility scale, with firms choosing locations to maximise utility. 
Bespoke model applications or proprietary modelling software may often mix and match different approaches meaning any particular modelling method may not simply fit into one of the identified modelling genres. Furthermore some model applications may incorporate both interregional and intraregional modelling. A land use transport interaction (LUTI) model would include one of the intraregional location models and sometimes an inter-regional model. For example the DELTA modelling package uses a utility based location model at the urban or intra-regional level and a multi-region inputoutput framework at the inter-regional level if inter-regional modelling is undertaken. Wegener (2014) provides a recent review of LUTI modelling.

There are also differences in the treatment of dynamics with some models taking a static analysis (MRIO, SCGE, spatial interaction and bid rent models) and others taking a dynamic approach (regional production function models and utility based location models). It is also clear that the models operate at very different spatial scales - this is implicit in Wegener's distinction between inter-regional and intraregional location models, but even within these categories models operate at very different scales with, for example, some location models simulating the actions of individual firms through microsimulation, and others taking a much broader spatial perspective. The field is also rapidly evolving, which to a certain extent is a reflection of the difficulties associated with the state of practice in regional economic modelling. For example, the interface between the transport model and the regional economic model can introduce complications to the modelling process particularly in the treatment of personal travel (as opposed to freight costs) (Bröcker and Mercenier, 2011; Tavasszy et al., 2011), and this of course is an area of particular interest to transport economists.

For transformational projects such as the Grand Paris Express it is very likely that several different modelling methods may need to be employed to try and understand the economic implications of the investments on GDP, productivity, employment and wages. The current state of the art in regional economic modelling does not offer a single model that meets all the needs of the analyst and decisionmaker for such projects. Clearly re-distributive effects are going to be large. Businesses (including universities) are expected to re-locate from central Paris to the areas served by the Grand Paris Express. LUTI models that focus on intra-regional (or urban) impacts will therefore be an essential tool. LUTI models however are typically used in a way that 'shuffles' activity around - thus pure growth stimulated by the investments is not modelled. For that additional tools are needed. Econometric approaches using regional production functions, MRIOs and SCGE models can all be used. The advantage of SCGE models over the other two is that they offer the ability to model the supply side constraints within the economy. Supply side constraints are likely to be very relevant in the context of such a large economic 'shock' as would be expected by the Grand Paris Express - in which case some of the growth maybe crowded out through higher prices (including wages). SCGE models are static equilibrium models and understanding the dynamics of growth and how workforce composition ${ }^{10}$ may change through investment may require alternative modelling methods - for example econometric production functions or productivity functions (see for example de Costa et al., 2012).

All these modelling methods are based around mathematical formulations. Such models will need to be supported by a narrative grounded in local evidence regarding the local economic conditions. Key to this narrative will be a demonstration of the availability of a workforce with the appropriate skills, or how skills will be enhanced through investment. If unemployment is expected to reduce as a consequence of the Grand Paris it will also be necessary to demonstrate that unemployed workers have the available skills to fill positions created by the Grand Paris. If they do not then supply side constraints may well crowd out some of the growth through wage inflation and re-distribution of the workforce towards the Grand Paris.

10 In terms of skills and occuptions. 


\subsection{Calculating total welfare impact}

Cost benefit analysis is usually undertaken in a partial equilibrium setting - see for example standard cost benefit analysis texts such as Boardman et al. (2011). As discussed previously within this environment it is usual to assume perfect competition outside of the primary market (i.e. in all markets other than transport marginal benefits equal marginal costs). This is the Transport CBA approach in Figure 4.1 in Chapter 4 and is appropriate for marginal schemes. Relaxing the assumption of perfect competition outside of the transport market means that surpluses in non-transport markets also need to be estimated. These surpluses in the CBA+ approach and the Total System approach also detailed in Figure 4.1 in Chapter 4 for non-marginal and transformational projects. In these situations there are two ways of estimating total welfare impact - an extension to partial equilibrium approach or through a multi-market general equilibrium analysis.

The partial equilibrium approach can be extended to the CBA+ or the Total System analysis by analysing each (non-transport) market distortion separately. The additional surplus to be estimated is equivalent to the difference between the marginal benefit and the marginal social cost for each additional unit of output, employment, etc. Thus for example under imperfect competition when prices are $20 \%$ above marginal social costs, the additional benefit of expanding output is $20 \%$ of the value of the expanded output. Similarly in a labour market distorted by a labour tax which leads to wages faced by the employer (the marginal product of labour) being 30\% above the net wage received by employees the additional surplus is $30 \%$ of the net wage received by the new employees (when employment expands). Local price and wage data need to be used for these estimations. The individual component surpluses are assumed additive and summed along with transport user benefits, changes in transport operators' producers' surplus and other externalities (safety and environment) to give the total welfare impact. The UK Department for Transport (DfT, 2005) uses this approach.

There are various issues with this approach. Aside from the sheer practical difficulty of achieving consistency between the transport user benefit estimates, including congestion and crowding feedbacks, and the wider impact estimates - which is a common challenge for any approach - the principal weaknesses are that the general equilibrium effects (overall expansion of the economy) are taken to be zero, and there exists the possibility that some double counting between the 'additional' surpluses may occur. Clearly the latter is less than ideal when we consider that in some cases certain market failures will exist concurrently affecting the same labour market segment. For example an expansion in labour supply among the low skilled would result in additional surpluses due to the presence of a labour tax, involuntary unemployment and search costs/thin labour markets. For transformational projects that lead to step changes in income the Marshallian consumer surplus measure estimated with this method will also overestimate the true welfare impact that is given by the Hicksian equivalent variation.

The alternative to partial equilibrium would be to undertake a spatial general equilibrium analysis. Such models in principle can accommodate multiple market failures, market interactions and income effects. Conceptually it would be preferable to model the wider economy impacts allowing product mark-ups and labour market conditions to vary across zones and sectors and this is what SCGE does. Also there can be consistency advantages of modelling within a set macroeconomic framework so that the funding costs are properly represented and the funding loop closed within the model. Unfortunately there have only been a few applications of SCGE models to transport schemes - we review the results from some of these in Annex.

With only a few applications of these methods there is a corresponding uncertainty in how robust their results are. Forsyth (2014) also identifies areas where these models require further development (e.g. in their representation of the labour market - which is a key source of additionality as we have identified). 
Furthermore these models have not been applied, as far as we are aware within a framework that captures all the elements of additionality we have discussed above. We have already argued that a general equilibrium analysis is likely to be necessary in the context of the Grand Paris Express in order to capture the effect of supply side constraints in the economy when estimating economic outcomes (i.e. GDP and employment changes). The need to examine multiple market failures simultaneously also points to the need for such a modelling tool.

To summarise when the relevant market failures are limited and step changes in incomes are not anticipated then an enhanced partial equilibrium analysis is likely to be adequate to estimate total welfare impact. Where multiple market failures are expected to interact (e.g. in the labour market) and income effects are expected to be relevant than a general equilibrium analysis is in principle necessary. The embryonic nature (in the context of transport appraisals) of general equilibrium models implies though that they should form just one part of the analytical process complementing more traditional methods (Forsyth, 2014).

\subsection{The relationship between welfare and GDP}

A number of authors have set out the different impacts of transport and whether they affect GDP/GVA or welfare or both (e.g. DfT, 2005a). When productivity increases real income (welfare) and real GDP both increase. Productivity increases occur through for example reductions in business and freight travel time, increases in agglomeration, and increases in knowledge spillovers. Changes in land values stimulated by a transport change affect GDP (if land rents alter) but do not affect welfare. Contrastingly time savings that facilitate purely social interactions (e.g. visiting friends and family) have a welfare effect but not a GDP effect. There are a host of impacts that affect both welfare and GDP but affect them in different ways. Safety has a GDP impact in that injury and death reduce both consumption and production of economic goods, but the welfare impact exceeds this 'economic cost' due to the presence of pain, grief and suffering. Carbon, air pollution and noise all have health impacts and so like safety have both GDP and welfare impacts, with the welfare impacts likely to exceed the GDP impacts. Changes in the natural environment (e.g. the landscape) may change welfare through changes in biodiversity, water quality, visual impacts, etc.

These will only have GDP impacts if the economy exploits these natural resources. Changes in commuting time are interesting due to the way they sit on the boundary between unpriced goods (nonwork time) and priced goods (hours of labour supplied to the labour market). Commuting time changes always have a welfare impact, but the GDP impact is determined by the structure of the labour market and local economy. In the monocentric urban model for example changes in commuting time only affect land rents. In such an environment commuting time changes will only be seen in GDP where housing is rented. If some commuting compensation occurs through the wage (e.g. in urban areas with multiple employment centres and in rural areas) then wages will fall in real terms and which will have an impact on GDP. Market frictions (e.g. sticky wages in real terms) will dampen these effects resulting in only some of these commuting benefits being passed through into GDP.

It is also important to recognise that the GDP/GVA impacts may also result in winners and losers. Mode shift from car to rail will increase the GVA of the rail sector and reduce the GVA of the car industry (car manufacturing, petrol wholesale and retail and vehicle servicing). Replacement of ferries with fixed links may increase the GVA of businesses located at either side of the ferry terminuses but will reduce the GVA of the ferry industry. When these impacts have a spatial and demographic related character distributional impacts become important too. 
Bringing this together and drawing from SACTRA (1999) it is clear that the GDP/GVA change and the welfare change metrics are not the same. Primarily they differ because, relative to CBA:

- GDP/GVA excludes non-market goods and bads such as unpriced environmental impacts and the element of safety benefits which is unpriced

- GDP/GVA excludes unpaid non-market production of goods and especially services from output

- GDP/GVA neglects changes in leisure and non-market work time, effectively assuming that the marginal resource cost of increased employment is zero.

Turning this around welfare metrics and GDP/GVA will only give the same measure if all factors are fixed (i.e. in the short run), there are no terms of trade effects and there are no externalities or unpriced goods (Blake, 2009 cited in Forsyth 2014).

Welfare evaluation of public projects has nearly half a century of codification behind it through various Manuals both generic (such as the UK Green Book) and sector specific (such as WebTAG). In contrast, direct calculation of GDP/GVA effects of transport projects is a relatively young industry and a more structured approach needs to be established for such issues as the treatment of displacement and leakage effects, the opportunity cost of spending public capital in one way relative to another, whether multiplier effects are or are not permitted. One particular point is that while the Net Present Value of a scheme is well accepted as a concept in CBA, frequently GVA calculations seem to be performed on the basis of single year model runs.

The exclusion of many unpriced impacts of transport (e.g. non-work time savings, pain grief and suffering) suggests that in the main the GDP impacts of transport projects will be smaller than the welfare impacts. Our review of the evidence base of transformational transport projects (see Annex) however suggests that this is not the case - or certainly it isn't the case in the context of transformational transport projects. Our review also gives examples where there can be a wide variation in the predictions made by economy models. This variation has previously been observed in the literature (e.g. Lakshmanan, 2011). The variation between different economy models and a lack of understanding regarding why GDP and welfare metrics differ undermines the credibility of the economy estimates, but also creates an environment in which outlandish claims of economic impact can influence decisions. This represents a severe challenge to the objective assessment of transformational transport schemes.

Our review of the case studies in Annex identifies five key sources of difference between different economy estimates and between CBA and economy metrics (additional to the conceptual differences discussed above). These are: the perspective from which the appraisal is undertaken, the treatment of economic potential (i.e. what supply side constraints are assumed), what the counterfactuals are, the use of local economic data, and ultimately differences between different economic models.

Perspective/Geography. The geography over which the economic impact is reported is relevant to the size of the impact. This is because the redistribution of economic activity can result in substantial transfers of employment and GDP at a local or sub-national level. A CBA is associated with net gains at a national level or even at an international level, whilst at the other extreme the economic impact approach used for the A82 investments would only report local impacts. The local perspective is therefore a significant explanatory of the disparity between the results from the cost benefit analysis approach and other modelling approaches. 
Economic Potential. What we mean by economic potential is the ability of a transport project to stimulate a number of structural changes to the economy, which would be accompanied by complementary investment in e.g. skills training, business premises, etc. This complementary investment would often be private sector developer driven, and would in turn generate further changes in output and employment. Some of the reduced form models in which people based productivity changes are included would be regarded as models of economic potential - for example the models developed by KPMG. The SASI model (referred to in Table ) could also be viewed as a model of economic potential. Similarly the economic impact approach used for the A82 is an economic potential method - as the growth forecast by these methods would typically require additional private sector investment. Cost benefit analysis on the other hand assumes that the marginal benefits of the ancillary investments equal the marginal costs and are therefore of no net value. The CGEurope model (referred to in Table ) is also argued to reflect the short run (Bröcker et al., 2004 p168-175) and therefore will produce lower estimates of economic growth than a model that considers long run growth.

It is also apparent that different models and methods treat supply side constraints in different ways. Some models are more limiting on growth than others - constraining the growth to availability of resources whether that be land availability or workforce availability. Such models are typically the LUTI models and the economic impact analyses as used in the A82. The reduced form models as applied by KPMG for HS2 and for the Northern Hub are fully unconstrained on the supply side (as they allow for unconstrained compositional change in the workforce and associated changes in land use).

Counterfactual. How the counterfactual is defined is also very relevant to the modelling methods and the results. In some instances the counterfactual is derived from regional economic models which include economic growth through supply side investment (albeit not modelled explicitly). In such instances arguably a model that just distributes that growth around (e.g. some LUTI models) is the most appropriate tool. In other instances the counterfactual may include no economic growth from supply side interventions - in which case a model which grows the economy is necessary. Clearly the different treatments of the counterfactual will give rise to different estimates of growth.

Use of local economic data. Cost benefit analyses often use standard values of time across the country despite wage rates and incomes varying significantly. This is often done on equity grounds. The user benefits in the cost benefit analysis are therefore estimated using these standard values, whilst the other GDP methods would typically use local data on e.g. earnings. Where earnings diverge significantly form national averages this would also give rise to significant differences between the economy modelling method based on CBA data and the other methods.

Differences between models. Undoubtedly differences between models exist - aside from the difference regarding whether economic potential is being modelled. Without a formal comparison between models and applications (to the same scheme) it is impossible for us to say why such differences exist. Even in the IASON ${ }^{11}$ study where two models were applied to the same set of schemes with the same inputs the study authors were only able to conject what the source of the differences were. For these two particular models they ascribed the differences to the specification of trade costs (including transport costs) across borders, the neglect of mobile capital in SASI and mobile labour in CGEurope, and that CGEurope is a static model directed primarily at short term responses, whilst SASI is a quasi-dynamic model which includes self-reinforcing cumulative effects (Bröcker et al., 2004 p168-175). Clearly these are 'technical' differences but appear to be critical in the model's performance. We also see that the two SCGE models applied for the Airports Commission give different results. Part of this difference has been ascribed to the different modelling approaches adopted. In the HMRC model seat demand/capacity drives the price of

11 Integrated Appraisal of Spatial Economic and Network Effects of Transport Investment and Policies. 
aviation and impacts on the rest of the economy, whilst in the PwC model the demand/capacity constraint leads to lower productivity in the aviation sector, which then impacts on the rest of the economy. These subtle differences appear to lead to the quite significant range in the GDP estimates. Including the productivity effect modelled in the $\mathrm{PwC}$ model in the HMRC model appears to increase the upper bound on GDP impacts in 2050 from $0.09 \%$ to $0.17 \%$ - a fairly significant increase (Airports Commission, 2013 pp98-99). Clearly therefore what mechanisms are being modelled makes a difference to the results. 



\section{Conclusions}

Some key messages from this paper are :

1. Transformational projects have a level of ambition and aspiration which make them qualitatively and quantitatively different from the general run of transport projects. Genuinely transformational transport projects are rare. Their key distinguishing features are that they operate both on zonal accessibility and on zonal attractiveness within the city region so that some combination of population, employment and economic structure will be materially different if the project is implemented from the business as usual scenario. There is no blueprint for the appraisal of transformational projects.

2. Conceptually the high level issues are at the level of alternative spatial economic futures for the region or nation. At this high level there are multiple challenges for modelling, forecasting and appraisal. These include definition of the counterfactual, representation of the economic system in which population, employment and income is contingent upon whether or not the scheme is undertaken, and crucially getting under the surface of concepts such as agglomeration to obtain a better understanding of the behaviour of the sectors whose responses to changes in accessibility and location attractiveness are key determinants of the outcome. The extent to which expansion of sectors such as banking and finance, higher education and hi-tech will draw on the regional, national and international labour markets is vital.

3. Inevitably we are discussing here a city region transport strategy which will take many years to build and many more years for the end users to respond fully to. Therefore there is a special need to consider the dynamics and interactions involved and the credibility of the timing of the responses assumed in the appraisal. We conjecture that this is a potential source of optimism bias; everything takes longer than expected.

4. Models can only take you so far; they should be viewed as useful tools. Different models are likely to give different results. The transparency and credibility with which they represent the linkages between accessibility change and economic system change is important. The ability to forecast structural change- both exogenous and endogenous to the project should not be exaggerated.

5. A clear narrative is crucial at high level within the project to describe what the analysts think could happen and what might happen if the project was not taken up; modelling and assessment is an input to that. 
6. Projects are frequently like Russian dolls. Inside the big doll—should we do this project—are smaller dolls which relate to timing, prioritisation, capacity, interchanges, alignment and other dimensions. Below the highest level, it becomes more credible to compare options within fixed assumptions for population, employment and income at regional level. So it may be sensible to think in terms of a suite of models - a high level strategic model with an accompanying appraisal of a Planning Balance Sheet style; a lower level model capable of comparing alternative plan options within the strategy; and local models designed to represent interactions with the road and public transport networks at particular key locations such as interchange points. Then, at any of those vertical levels, more than one model to represent the system may be required. For example Land-Use and Transport Interaction approaches and Spatial Computable General Equilibrium approaches may offer complementary insights. 


\section{Bibliography}

Airports Commission (2013) Airports Commission: Interim report. Report dated December 2013.

Boardman, A.E., D.H. Greenberg, A.R. Vining and D.L. Weimer (2011) Cost-Benefit Analysis Concepts and Practice. Fourth Edition. Upper Saddle River: New Jersey.

Cheshire, P. C. and Sheppard, Stephen Charles (2005) The introduction of price signals into land use planning decision-making : a proposal. Urban Studies, 42 (4). 647 -663. ISSN 1360-063X

Badinger, H. (2007) Has the EU's Single Market Programme Fostered Competition? Testing for a Decrease in Mark-up Ratios in EU Industries. Oxford Bulletin of Economics and Statistics, 69(4), pp.497-519.

Bhaskar, V., A. Manning and T. To. (2003) Oligopsony and monopsonistic competition in labor markets. Journal of Economic Perspectives, 16(2), pp.155-174.

Bröcker, J., Meyer, R., Schneekloth, N., Schürmann, C., Spiekermann, K., Wegener, M. (2004): Modelling the Socio-economic and Spatial Impacts of EU Transport Policy. IASON (Integrated Appraisal of Spatial economic and Network effects of transport investments and policies) Deliverable 6. Funded by 5th Framework RTD Programme. Kiel/Dortmund: Christian-Albrechts-Universität Kiel/Institut für Raumplanung, Universität Dortmund.

Bröcker, J. and J. Mercenier (2011) General Equilibrium Models for Transportation Economics. In: de Palma, A., R. Lindsey, E. Quinet, and R. Vickerman (eds) A Handbook of Transport Economics. Chapter 2 pp21-65. Cheltenham: Edward Elgar

Card, David and Alan B. Krueger "Minimum Wages and Employment: A Case Study of the Fast-Food Industry in New Jersey and Pennsylvania." American Economic Review, 84(4), pp. 772-93.

Christopoulou, R., And P. Vermeulen (2008) Markups in the Euro Area and the US Over the Period 1981-2004: A Comparison of 50 Sectors. ECB Working Paper No. 856. Report dated January 2008.

Commissariat Général à la Stratégie et à la Prospective (2013) Cost Benefit Assessment of Public Investments Final Report

Department for Business, Innovation and Skills (BIS) (2009) RDA evaluation: Practical Guidance on Implementing the Impact Evaluation Framework. December 2009. London: BIS.

Department for Transport. (2005a) Transport, Wider Economic Benefits and Impacts on GDP. London: Department for Transport.

Department for Transport. (2005b) Guidance on Value for Money. London: Department for Transport.

Department for Transport. (2012) Wider impacts sub-objective. WebTAG Unit 3.5.14 (under consultation). London: Department for Transport.

Department for Transport (DfT) (2012) Economic Case for HS2: Updated appraisal of transport user benefits and wider economic benefits. A report to Government by HS2 Ltd. January 2012. Available 
online at: < http://www.dft.gov.uk/publications/hs2-economic-case-appraisal-update/> (Accessed 26th October 2012).

Department for Transport 2013 https://www.gov.uk/government/consultations/national-road-and-railnetworks-draft-national-policy-statement

Elhorst, J.P. and J. Oosterhaven. (2008) Integral cost-benefit analysis of Maglev projects under market imperfections. Journal of Transport and Land Use, 1(1), pp. 65-87.

European Commission. (2008) Guide to cost-benefit analysis of investment projects. Structural Funds, Cohesion Fund and Instrument for Pre-Accession. Brussels: Directorate General Regional Policy.

Findeis, J.L. and L. Jensen. (1998). Employment opportunities in rural areas: implications for poverty in a changing policy environment. American Journal of Agricultural Economics, 90(5), pp. 1000-1007.

Forsyth, P. (2014) Using CBA and CGE in Investment and Policy Evaluation: a Synthesis. Draft report to the International Transport Forum. Report dated march 2014.

GMPTE (2010) Network Rail Northern Hub Rail Study. Report to Greater Manchester Integrated Transport Authority Policy and Resources Committee. Report dated 19th March 2010.

Graham, D.J. (2007). Agglomeration, productivity and transport investment. Journal of Transport Economics and Policy, 41(3), pp. 317-343.

Graham, D.J. (2009). Identifying urbanisation and localisation externalities in manufacturing and service industries. Papers in Regional Science, 88(1), pp. 63-84.

Grimes, A. and Y. Laing (2010) A Bridge to Somewhere: Valuing Auckland's Northern Motorway Extensions. Journal of Transport Economics and Policy 44(3), pp. 287-315

Harris, R.I.D. (1999). Incidence of imperfect competition in UK sectors and regions. In: SACTRA (ed). The welfare implications of transport improvements in the presence of market failure and the incidence of imperfect competition in UK sectors and regions. London: Department for the Environment, Transport and the Regions, pp. 77-90.

Haveman, R.H. and S. Farrow. (2011). Labor expenditures and benefit-cost accounting in times of unemployment. Journal of Benefit-Cost Analysis, 2(2) Article 7.

High Speed 2 Ltd (HS2) (2012) Updated Economic Case for HS2. Report dated August 2012.

Hotelling, H. (1929). Stability in competition, Economic Journal, 39, pp41-57

Jara-Diaz, S.R. (1986). On the Relation between Users' Benefits and the Economic Effects of Transportation Activities. Journal of Regional Science. 26(2), pp.379-391.

Johnson D., Mackie P. and Shires J. (2014) Buses and the Economy. Report for Greener Journeys, London.

Jones, P., T. Eyers, J. Bray, N. Georgeson, T. Powell, J. Paris and R. Lane (2004) The Jubilee Line Extension Impacts Study Main Findings and lessons learnt. European Transport Conference. London:AET Transport

King, A. (2012) Economy-wide impacts of industry policy. NZ Treasury Working Paper 12/05. 34pp

KPMG (2013) HS2 Regional Economic Impacts. Report prepared for HS2 Ltd. September 2013.

Lakshmanan, T. R. (2011). The broader economic consequences of transport infrastructure investments. Journal of Transport Geography, 19(1), 1-12. 
Leontif, W. (1966) Input-Output Economics. Oxford: Oxford University Press.

Mackie P and Worsley T. (2013) International Comparisons of Transport Appraisal Practice. Report to UK Department for Transport.

Mackie P., Worsley T. and Eliasson J. (2014 forthcoming) Transport Appraisal Revisited, Research on Transport Economics (RETREC)

Manning, A. (2003). Monopsony in Motion: Imperfect Competition in Labor Markets. Princeton, NJ: Princeton University Press.

MVA/ITS (2013) Assessment of Methods for Modelling and Appraisal of the Sub-National, Regional and Local Economy Impacts of Transport. Report to the Department for Transport. September 2013.

Nash, C.A. and P.J. Mackie. (Unpublished, 1990) Measuring the Benefits of Transport Access Projects. Report to the Department of Environment. ITS, University of Leeds, UK

Odgaard, T., Kelly, C.E. and Laird, J.J. (2005) Current practice in project appraisal in Europe. European Transport Conference 3-5 October 2005, Strasbourg. London: AET Transport

Office for National Statistics (ONS) (2010) Measuring the economic impact of an intervention or investment. Paper Two: Existing sources and methods. London: ONS.

Oosterhaven, J. and T. Knaap (2003) Spatial Economic Impacts of Transport Projects. In: Pearman, A., P. Mackie, J. Nellthorp and L. Giorgi (eds) Transport Projects, Programmes and Policies: Evaluation Needs and Capabilities. Chapter 5. Aldershot: Ashgate.

Overman, H., S. Gibbons, S. D’Costa, G. Mion, P. Pelkonen, G. Resende and M. Thomas (2009) Strengthening the economic linkages between Leeds and Manchester. Report to Northern Way. Report dated November 2009.

Oxford Economics (2012, Unpublished) The value of aviation connectivity to the UK. March 2012. A report prepared for BAA. Available online at:

http://mediacentre.heathrowairport.com/imagelibrary/downloadmedia.ashx?MediaDetailsID=887\&SizeI $\underline{\mathrm{d}=-1}$ (accessed 13th September 2012).

Pilegaard, N. and M. Fosgerau. (2008). Cost benefit analysis of a transport improvement in the case of search unemployment. Journal of Transport Economics and Policy, 42(1),pp. 23-42.

Quinet E. (2014) Le Projet du Metro 'Grand Paris' : une evaluation. Futuribles forthcoming

Richards, T., R.N Acharya and A. Kagan. (2008). Spatial competition and market power in banking. Journal of Economics and Business 60(5) pp436-454

Rietveld, P. and Bruinisma, F. (1998) Is transport infrastructure effective? Transport Infrastructure and Accessibility: Impacts on the Space Economy. Springer Verlag: Berlin.

Rogerson, R., R. Shimer and R. Wright. (2005). Search-Theoretic Models of the Labor Market: A Survey. Journal of Economic Literature, 43, pp.959-988.

SAHA (2010). Roads of National Significance Economic Assessments Review. Report to NZTA. Report dated July 2010.

Steer Davies Gleave (2009 Unpublished) The Northern Way: Manchester Hub Phase 1 - Transport Modelling and Benefit Assessment. Report to Northern Way. Report dated April 2009. 
Standing Advisory Committee on Trunk Road Assessment (1999) Transport and the Economy. Norwich:TSO.

Tavasszy, L. A., M. J. P. M.Thissen and J. Oosterhaven (2011). Challenges in the application of spatial computable general equilibrium models for transport appraisal. Research in Transportation Economics, 31(1), pp12-18.

Venables, A.J. and M. Gasiorek. (1999). The Welfare Implications of Transport Improvements in the Presence of Market Failure. In: SACTRA (ed). The welfare implications of transport improvements in the presence of market failure and the incidence of imperfect competition in UK sezaxctors and regions. London: Department for the Environment, Transport and the Regions, pp. 3-58.

Venables, A.J. (2007). Evaluating urban transport improvements: cost-benefit analysis in the presence of agglomeration and income taxation. Journal of Transport Economics and Policy. 41(2), pp. 173-188.

Venables, A.J., J.J. Laird and H.G. Overman (2014) Transport Investment and Economic Performance. Report to the Department for Transport.

Vickerman, R. (ed.) (1991) Infrastructure and Regional Development. Pion: London.

Wegener M (2004) Overview of land-use transport models. In: Hensher D.A. and K.J. Button (eds) Transport geography and spatial systems. Handbook 5 of handbook in transport. pp 127-146. Kidlington: Pergamon/Elsevier Science.

Wegener, M. (2011). Transport in spatial models of economic development. In: de Palma, A., R. Lindsey, E. Quinet, and R. Vickerman (eds) A Handbook of Transport Economics. Chapter 3, pp46-66. Cheltenham: Edward Elgar

West Yorkshire Passenger Transport Executive (WYPTE) (2014) West Yorkshire and York LTB Priority Core Package of Schemes and GVA and BCR Measures.

Wilson, A.G. (1998) Land-Use/transport Interaction Models: Past and Future. Journal of Transport Economics and Policy 32(1) pp3-26.

Worsley T (2011) The evolution of London's Crossrail Scheme and the development of the Department for Transport's economic appraisal methods Discussion Paper No. 2011-27 International Transport Forum, Paris

Zhu, J., J. Ying and M. Echenique (2012) Application of a new spatial computable general equilibrium model for assessing strategic transport and land use development options in London and surrounding regions. ERSA congress 2012, August 2012, Bratislava. 


\section{Annex: Selective review of welfare and economic outcomes from transformational transport investments}

We have found it hard to make direct comparisons between modelling methods as it is rare that different modelling methods are applied to the same scheme appraisal simultaneously. Invariably there are subtle but important differences between the scenarios that are being examined. In the main therefore our survey compares the economic outcomes in terms of GDP impacts with the CBA welfare estimates. These welfare estimates include the agglomeration, labour tax and imperfect competition wider economic impacts discussed in section 3. Our review is based principally around UK evaluations, though we do draw on international examples in places where these add value to the review.

\section{A.1 Ex post studies}

Ex post studies can act as a form of validation on modelling methods. Unfortunately appropriate ex post studies are limited, and where they exist there are not necessarily economic modelling studies against which they can be compared. There do exist two examples which we are aware of where economic outcomes in terms of GDP can be compared against cost benefit analyses. The first is that of the Jubilee Line Extension, where Jones et al. (2004) concluded that it was responsible for adding some £9.6b to GDP (2003 prices present value over 60 years from 2000 to 2060) through attracting jobs to the area and through agglomeration benefits. Other ex post work identified that the ex post CBA benefit cost ratio was 1.75 (Bartlett School of Planning, undated) and the final scheme costs were £3.5billion (Worsley, 2011). That is the gain to the economy exceeds the CBA benefits even though the CBA benefits include nonGDP impacts (non-work time savings, accident savings, etc.). A similar finding was found for the extension of the Northern motorway in Auckland where after taking into account reductions in property values elsewhere in Auckland the motorway developments led to an increment in land values such that the scheme had generated a GDP benefit to cost ratio of 6.3. This substantially exceeded the benefit to cost ratio from the CBA (Grimes and Liang, 2010).

\section{A.2 Capacity investments}

The provision of a high speed rail line from London to Birmingham, Manchester and Leeds (HS2) is regarded as an investment that will provide a step change in the rail capacity of the UK. For this investment KPMG (2013) estimated an increase of GVA to the national economy of $£ 15$ billion per annum as estimated with a reduced form production function model. Overman et al. (2009 Chapter 6) find benefits just under half of that at $£ 7$ billion (2006 prices) estimated with a general equilibrium model - albeit for a scheme that only reduces journey times from Manchester and Leeds. In contrast the present value of benefits from the CBA is expected to be $£ 63.6$ billion (over a 60 year period) (HS2, 2012 p3) - a large proportion of which will not be business related. That is the 60 year benefits (albeit discounted) are expected to only be 4 times a single year's GVA gain (as estimated by KPMG).

Undoubtedly the fact that transport tends to re-distribute economic activity, means that local impacts can be very high. For example the Northern Hub (a significant expansion of rail capacity in Manchester) is estimated to generate an additional £2.1billion in GDP for the North of England using a reduced form 
productivity model ${ }^{12}$. Of this $£ 0.9$ billion is additional to the UK economy (GMPTE, 2010). However, even here the projected GVA gain at a national level seems to be much higher than the expected present value of benefits from the cost benefit analysis - where 60 year present value of benefits is estimated to be $£ 12.7$ billion (SDG, 2009 p76), i.e. the 60 year benefits (albeit discounted) are only 13 times greater than a single year's national GVA gain and only 6 times larger than a single year's regional GVA gain.

The $£ 1$ billion West Yorkshire Transport Fund comprising of some 28 transport infrastructure projects/packages in the West Yorkshire area of England has an estimated regional GVA impact of £1.23 billion creating about 20,000 jobs by $2036.46 \%$ of this gain is estimated to be additional at the national level. This has been estimated using a simulation based LUTI model. In contrast the CBA only has a benefit cost ratio of 4.9 (WYPTE,2014). That is the benefit from the CBA (including non-business related benefits) is only 4 times a single years regional GVA impact and just under 8 times the additional impact at a national level.

In New Zealand SAHA (2010 Appendix D) used a CGE model to study the impact of upgrades to strategic roads of national significance, showing that total benefits could be $80 \%$ above user benefits. This is a long run expected return as it requires investment in other industries to be stimulated by the transport infrastructure investment.. In contrast a study by SAHA (2010 Appendix C), employing partial equilibrium techniques to capture agglomeration and labour supply effects, estimated the wider economic benefits of the same strategic roads to be $40 \%$ of the user benefits.

\section{A.3 International orientated investments}

Airports are a critical part of a nation's infrastructure that facilitate international trade. For another major infrastructure project, expansion of Heathrow Airport through the construction of a third runway, it has been argued that if it is not expanded economic activity in the UK (as measured by GDP) would be reduced by $£ 8.5$ billion each year and employment would be lower by 141,400 (compared to an unconstrained case) as estimated with a general equilibrium model (Oxford Economics, 2012). Much of this economic activity is no doubt transferred from hubs elsewhere in the world, but still it is an economic gain to the UK. In contrast the 60 year present value of benefit from the cost benefit analysis for all airport capacity constraints across the UK is estimated to be $£ 18$ to $£ 20$ billion, whilst a 60 year present value of GDP benefit estimated from two different SCGE models is in the region of $£ 30$ to $£ 45$ billion (Airports Commission, 2013 p100).

At a much smaller scale the upgrade of the A82 to Fort William in the Scottish Highlands is expected to generate a $£ 152$ million increase in regional GDP (30 year PV) of which $£ 113$ million is additional at the national level. The CBA in contrast only has $£ 52.5$ million of business and freight user benefits. The additionality is created as the road serves an export orientated sector (fish farming) - therefore whilst the majority of the traffic on the road is not international the core businesses that it serves have an international focus. The additionality was estimated using a typical economic impact analysis approach that examines the underlying economic and market conditions and makes estimates on additionality and displacement (BIS, 2009).

The above examples, aside from the HS2 example, are in the main comparisons between an economy modelling method (e.g. reduced form) and the use of CBA outputs as a proxy for economy impacts. This is because it is hard to find examples where two transport-economy modelling methodologies are employed simultaneously for the same set of projects using exactly the same set of inputs. The only study we have identified is that undertaken as part of the IASON research project (Bröcker et al., 2004).

12 Productivity is taken to be a function of accessibility to economic mass and other factors. 
The results from the comparison between the economy modelling of these trans-European projects (outlined in Table 1) using a regional production function model (SASI) and a spatial computable general equilibrium model are reproduced in Table 1 for 13 different investment and transport policy scenarios. The second column represents the degree of correlation between the two models' results for changes in GDP/capita at a NUTS3 regional level ${ }^{13}$. As can be seen this is not particularly high, but they do show broad agreement in terms of the direction and spatial location of change. The right hand column represents the average difference between GDP/capita changes forecast by the two models. Taking scenario A1, implementation of all Trans-European Network (TEN) priority projects (Essen list), a value of 5.05 means that the SASI model suggests GDP/capita growth 5.05 times that predicted by CGEurope. However it is clear that there is no consistency between the scenarios - with SASI predicting a 9.1 times larger GDP/capita growth in one scenario, and at the other extreme CGEurope predicting a GDP/capita growth 3.3 times that predicted by SASI $(=1 / 0.30)$. Clearly therefore there is very little agreement between what one would expect to be two fairly sophisticated modelling methods.

13 There are 1,324 NUTS3 areas in the EU (28 countries) 
Table 1. A comparison of GDP/capita impacts between a regional production function model (SASI) and a Spatial Computable General Equilibrium model (CGEurope) across multiple European transport investment scenarios

\begin{tabular}{|c|c|c|c|}
\hline \multicolumn{2}{|c|}{ Scenario } & \multicolumn{2}{|c|}{ Relative Change of GDP Per Capita } \\
\hline & & $\begin{array}{l}\text { Coefficient of } \\
\text { Correlation } \\
\text { between SASI and } \\
\text { CGEurope results }\end{array}$ & $\begin{array}{l}\text { Regression } \\
\text { Coefficient of SASI } \\
\text { results on } \\
\text { CGEurope results }\end{array}$ \\
\hline A1 & $\begin{array}{l}\text { Implementation of all Trans-European Network (TEN) priority } \\
\text { projects (Essen list) }\end{array}$ & 0.47 & 5.05 \\
\hline A21 & Implementation of all high-speed rail priority projects (Essen list) & 0.70 & 9.10 \\
\hline A22 & $\begin{array}{l}\text { Implementation of all conventional rail priority projects (Essen } \\
\text { list) }\end{array}$ & 0.68 & 4.64 \\
\hline A23 & Implementation of all road priority projects (Essen list) & 0.80 & 1.76 \\
\hline A24 & Implementation of all rail priority projects (Essen list) & 0.62 & 8.17 \\
\hline A3 & Implementation of all TEN and TINA projects & 0.50 & 5.62 \\
\hline A4 & Implementation of all TEN projects & 0.56 & 5.10 \\
\hline B1 & Social Marginal Cost pricing applied to road freight & 0.08 & 0.30 \\
\hline B2 & $\begin{array}{l}\text { Social Marginal Cost pricing applied to all modes (travel and } \\
\text { freight) }\end{array}$ & 0.73 & 2.36 \\
\hline $\mathrm{C} 1$ & $\begin{array}{l}\text { Implementation of all TEN priority projects (Essen list) plus } \\
\text { Social Marginal Cost pricing applied to all modes (travel and } \\
\text { freight) }\end{array}$ & 0.69 & 1.87 \\
\hline D1 & Dedicated rail freight network & 0.46 & 3.64 \\
\hline $\mathrm{E} 1$ & TIPMAC business-as-usual scenario & 0.52 & 5.80 \\
\hline E2 & TIPMAC fast implementation scenario & 0.70 & 0.89 \\
\hline
\end{tabular}

Source: Bröcker et al. (2004 Table 5.1 p168) 


\section{EInternational Transport Forum}

\section{Appraising Transformational Projects The Case of the Grand Paris Express}

A well-executed economic appraisal can demonstrate to the decision maker whether investment in a project represents a good use of resources and inform the decision to approve the scheme, postpone it or reject it. But the micro-economic partial equilibrium foundations of cost-benefit analysis are challenged by projects such as the Grand Paris Express, a scheme which is intended to transform the level of economic development in the area it will serve.

There are multiple challenges for modelling, forecasting and appraisal. These include definition of the counterfactual do-nothing or do-something-else case and representation of the economic system in which population, employment and income is contingent upon whether or not the scheme is undertaken. Crucially, the practical implications of concepts such as the economic benefits of agglomeration have to be unravelled to predict the behaviour of the sectors whose responses to changes in accessibility are key determinants of the outcome of investment in the project.

The aim of this report is to review the conduct of appraisal in these challenging conditions.

This report is part of the International Transport Forum's Country-Specific Policy Analysis (CSPA) series. These are topical studies on specific transport policy issues of concern to a country carried out by ITF on request. 